\title{
Crise financeira americana e as políticas monetárias não-convencionais *
}

\author{
Paulo José Saraiva \\ Luiz Fernando de Paula \\ André de Melo Modenesi ${ }^{* * * *}$
}

\begin{abstract}
Resumo
O artigo tem por objetivo analisar o amplo conjunto de políticas monetárias não-convencionais adotadas nos EUA a partir da crise financeira de 2007-2008, focalizando aspectos conceituais, detalhamento dos programas adotados pelo FED e sua efetividade. Sustenta-se que a utilização de políticas de crédito e quase débito tiveram efeitos significativos sobre as condições financeiras e um conjunto de variáveis macroeconômicas nos EUA, como produto e emprego. Tal resultado levanta questionamentos sobre a efetividade da política monetária convencional e da orientação para frente da política monetária, que eram elementos centrais à visão do Novo Consenso Macroeconômico que antecedeu a crise financeira 2007-2008.
\end{abstract}

Palavras-chave: Novo consenso macroeconômico; Política monetária; Política de afrouxamento monetário; FED; Crise financeira internacional.

\section{Abstract \\ The American financial crisis and non-conventional monetary policies}

The paper aims to analyze the wide range of unconventional monetary policies adopted in the U.S. since the 2007-2008 financial crises, focusing on conceptual aspects, the implementation of different programs and measures adopted by FED, and their effectiveness. It is argued that the use of credit and quasi-debt policies had significant effects on the financial conditions and on a set of macroeconomic variables in the US, such as output and employment. This result raises questions about the effectiveness of conventional monetary policy and the forward guidance, both of which were key elements in the New Macroeconomics Consensus view that preceded the 2007-2008 financial crisis.

Keywords: New consensus macroeconomics; Monetary policy; Quantitative easing; FED; International financial crisis.

JEL F49, G01.

* Artigo recebido em 20 de outubro de 2014 e aprovado em 21 de julho de 2016. Os autores agradecem as sugestões do parecerista anônimo, isentando-o de erros e omissões remanescentes.

** Professor Assistente do Instituto Três Rios da Universidade Federal Rural do Rio de Janeiro (ITR / UFRRJ). Seropédica, RJ, Brasi. E-mail: pjsaraiva@terra.com.br.

**** Professor Titular da Faculdade de Ciências Econômicas da Universidade do Estado do Rio de Janeiro

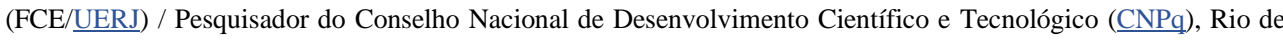
Janeiro, RJ, Brasil. E-mail: luizfpaula@terra.com.br.

**** Professor Adjunto do Instituto de Economia da Universidade Federal do Rio de Janeiro (IE/UFRJ) / Pesquisador do CNPq, Rio de Janeiro, RJ, Brasil. E-mail: amodenesi@ gmail.com. 


\section{Introdução}

A década que antecedeu a crise financeira americana de 2007-2008 alcunha de "grande moderação" e, segundo Bernanke (2004), a política econômica guiada por um regime de metas de inflação era capaz de domesticar os ciclos econômicos. Ele argumentou que os países que adotaram este modelo ou uma variante deste regime, como os EUA e outros países industrializados, tiveram ao longo dos anos de 1990 e até meados de 2000, uma forte redução na variabilidade do produto e da inflação. No caso americano, a volatilidade do produto teve uma redução de $50 \%$ e a taxa de crescimento média foi superior a $3 \%$ a.a., ao passo que a volatilidade da inflação recuou cerca de $2 / 3$.

Contudo, a ruptura no sistema financeiro americano que eclodiu em setembro de 2007 e agravou-se a partir de setembro de 2008, promoveu uma crise sistêmica que impactou sobremaneira na economia mundial. Tecnicamente a recessão americana começou em dezembro de 2007 e se estendeu até junho de 2009, embora os indicadores econômicos para a economia norte-americana permaneceram posteriormente abaixo do período que antecede a crise. Registrou-se um crescimento econômico entre 2007 e 2014 de apenas 1,2\% a.a., ao passo que a inflação média não ultrapassou $1,7 \%$ a.a. No mercado de trabalho observaram-se os piores resultados com a taxa de desemprego subindo de 5\% em 2006 para cerca de $10 \%$ em 2009, 7,4\% em 2013 e fechando o ano de 2014 em 6,2\% (IMF, 2015).

Contudo, o reestabelecimento das operações nos mercados financeiros, assim como a retomada do crescimento e do emprego, não ocorreram por meio das forças de mercado, tendo sido necessária a utilização de um amplo conjunto de políticas monetárias convencionais (PMC) e não-convencionais (PMNC). Esta primeira é equivalente à política de juros, ao passo que as medidas não convencionais podem ser identificadas com políticas de balanço e subdividem-se em políticas de crédito (emprestador de última instância) e política de quase débito, sendo que está última permaneceu ativa até outubro de 2014, quando finalmente foi extinta pelo banco central americano (Fed). Ressalta-se que as PMNC foram essenciais, particularmente pelo fato do principal instrumento de PMC - políticas de juros (as operações de mercado aberto) - ter-se tornado sem efeito mesmo antes das taxas de juros de curto de prazo terem se aproximado de zero no final do ano de 2008. Assim, a partir da crise que seguiu a quebra do banco Lehman Brothers, em setembro de 2008, a forte expansão (e mudança na sua composição) do balanço do Fed se tornou o principal instrumento de política monetária, seja através da concessão de empréstimos de liquidez seja via aquisição de títulos do Tesouro e das agências semipúblicas - Fannie Mae, Freddie Mac e Ginnie Mae (Bullio et al., 2010, p.342), além da troca de títulos do Tesouro de longo prazo por títulos de curto prazo. 
Este artigo tem por objetivo analisar o amplo conjunto de PMNC adotadas nos EUA a partir da crise financeira de 2007-2008. Para este propósito, está subdividido em três seções, além desta introdução. A seção 1 discute e define alguns aspectos teóricos relacionados às PMC e PMNC. A seção 2, por sua vez, examina o amplo conjunto de PMNC adotadas na economia americana ao longo do período de 2007 a 2013, além dos impactos destas sobre o balancete do Fed. Já a seção 3 avalia a literatura empírica acerca da efetividade destas políticas de crédito e quase débito sobre a melhoria das condições gerais dos mercados financeiros, de mercados específicos, bem como dos impactos sobre um conjunto de variáveis macroeconômicas nos EUA. Seguindo-se a conclusão do artigo.

\section{Aspectos teóricos e conceituais das políticas monetárias convencionais e não convencionais}

O Novo Consenso Macroeconômico ${ }^{1}$ (NCM) é um construto teórico e metodológico da escola novo-keynesiano que se propôs a criar uma "ciência monetária" a partir de elementos de diversas concepções teóricas, como os monetaristas, novos clássicos, ciclos reais de negócios, além de seus próprios desenvolvimentos. O produto resultante desta síntese foi implantado por meio de mudanças institucionais e operacionais na condução da PMC, através da definição do objetivo primordial do banco central (BC) de promoção da estabilidade de preços, tendo para tanto adquirido a autonomia operacional para perseguir tal objetivo.

Em termos operacionais a regra de Taylor sintetiza esta mudança, na qual a inflação é definida como a âncora nominal da PMC, uma vez que tanto a taxa natural de desemprego, quanto à taxa de juros de equilíbrio não são passiveis de determinação (Davidson, 2006). Ademais, o fim do regime de câmbio fixo no início da década de 1970 (Bretton Woods) e as limitações encontradas na adoção de metas monetárias na década de oitenta, em virtude das inovações financeiras e das variações não previsíveis na velocidade de circulação da moeda, impuseram sérias restrições à condução da política monetária com base em regras monetárias.

A partir da nova regra de condução PMC, a manipulação da taxa de juros de curto prazo e a comunicação com o público são definidas como os instrumentos operacionais e convencionais da PM. Estas são alteradas, quando necessário, para afetar as metas intermediárias - taxa de juros de longo prazo e as expectativas de inflação - e deste modo à demanda no curto prazo, dado que no longo prazo a PM é

(1) A seguir são apresentados alguns autores e publicações que defendem a existência de um núcleo comum e convergente de pesquisas em macroeconomia pré-crise: Blanchard (1997); Blinder (1997); Taylor (1997); Bernanke (2004); Meyer (2001); MacCallum (2002); Goodfriend (2007) e Woodford (2009). 
neutra, tendo como objetivo final uma inflação baixa e estável. Esta configuração de PMC é denominada de "regime de metas de inflação".

Ressalta-se, que embora tenham sido enfatizados outros canais pelos quais a PMC é transmitida à demanda agregada, como exposto por Bernanke e Getler (1995), os mecanismos de transmissão foram simplificados aos impactos da taxa de juros de curto prazo sobre as expectativas de inflação e as taxas de juros reais longas e, deste modo, sobre a substituição intertemporal dos agentes (consumo presente ou futuro), de modo similar ao modelo padrão IS/LM, porém incorporando o canal de expectativas. Nesta nova configuração de PMC, os canais de crédito amplo e restrito, além da taxa de câmbio, não foram ignorados, mas supõe-se que estes se moveriam de forma previsível e estável às mudanças na taxa básica de juros (Meyer, 2001; Goodfriend, 2005). Essa simplificação representa a "doutrina Greenspan"2 e a aceitação da hipótese de mercados eficientes pelo NCM (Bernanke; Getler, 1999, 2001), além da irrelevância da manipulação da oferta monetária como variável operacional da PM.

Como resultado desta simplificação, o modelo teórico do NCM suprimiu a equação do mercado monetário (LM), substituindo-a pela regra de Taylor. A principal implicação deste modelo é de que a moeda não importa e deste modo, em tese, a PMNC, particularmente as compras de ativos, não teriam nenhum impacto sobre a atividade econômica, pois a taxa de juros de longo prazo e as expectativas dependem da taxa de juros de curto prazo, além da comunicação que está sujeita à credibilidade de um BC. A única alternativa para uma situação na qual a PMC perde a sua efetividade (i.e, quando a taxa de juros de curto prazo está próxima a zero ${ }^{3}$ ) é a "forward policy guidance", informando aos agentes sobre as intenções futuras desta (Eggertsson; Woodford, 2003).

O NCM limitou o escopo de atuação da política monetária. Sua operacionalização foi circunscrita ao uso das operações de mercado aberto - que se tornou o principal instrumento da PM - e ao gerenciamento das expectativas dos agentes econômicos. Assim, conferiu-se um papel secundário aos demais instrumentos de política monetária, com destaque para o fato de que o recolhimento de depósitos compulsórios foi virtualmente abolido na maioria dos países desenvolvidos, no período anterior à crise.

(2) De um modo geral a "doutrina Greenspan" defendia a atuação do BC após a ruptura da bolha (para "limpar"), ao invés da atuação preventiva "inclinar-se contra o vento".

(3) Quando o mecanismo de transmissão via canal de taxa de juros perde o seu efeito, o BC perde a capacidade de reduzir os spreads de juros de longo prazo, uma vez que não consegue achatar a estrutura a termo da taxa de juros e o prêmio de risco, e desta forma, o BC perde a capacidade de estimular a demanda agregada e produto. Ademais, os canais de crédito, de câmbio, de preços dos ativos e dos preços relativos deixam de operar via taxa básica, limitando ainda mais a PM. 
Ressalta-se que o Fed, até o período pré-2008, manteve um percentual de exigência de reservas mínimas ${ }^{4}$ (compulsório). Este foi justificado pela necessidade de maior segurança nas operações financeiras, apoiando as transferências de recursos entre as instituições, bem como desempenhava um importante papel na operacionalização da PMC, no sentido (no caso do compulsório) de auxiliar a estabilidade da demanda por reservas bancárias e assim facilitar a ação do BC na fixação da taxa de juros.

Já as operações de redesconto e empréstimo de liquidez funcionam em vários países como uma "válvula de segurança" colocada à disposição dos bancos depositários para solucionar problemas individuais de caixa que venham a ocorrer no final do dia ou no final do período de movimento do recolhimento compulsório (Carvalho et al., 2015, cap. 11, 12).

Contudo, a crise financeira de 2007-2008 trouxe questionamentos ao arcabouço teórico ${ }^{5}$ e deslocando este dos procedimentos operacionais do NCM em relação à factibilidade do "forward policy guidance" em contraponto à efetividade das PMNC. Ressalta-se que estas tiveram um importante papel no reestabelecimento de mercados financeiros, além do estímulo à atividade econômica e ao emprego. As políticas de crédito $^{6}$ nos EUA extrapolaram, em muito, a magnitude da PMC normalmente observada em tempos normais, bem como foram estendidas para instituições não depositárias, ampliando a atuação do BC no mercado de capitais.

(4) O Fed determina o compulsório sobre o passivo das instituições depositárias, sendo as faixas percentuais de $0 \%, 3 \%$ e $10 \%$.

(5) A crise financeira abalou a estrutura teórica do NCM e vem provocando um debate de revisão (rethinking) na ortodoxia, em especial nos EUA, um movimento em boa medida capitaneado pelo FMI (Blanchard et al., 2010, 2013) e autores neoclássicos mais críticos ao NCM, tais como Einchengreen, Krugman e Stiglitz. Cabe ressaltar que Taylor (2010a, 2010b) reafirma os mesmos preceitos teóricos e orientações de política econômica do NCM, sustentando que a crise foi causada pelo desvirtuamento das políticas convencionais. Minskhin (2010, p. 32), por sua vez, afirma: "The arguments supporting central banks' adhering to the principles of the new neoclassical synthesis are still every bit as strong as they were before the crisis". Para uma discussão sobre o debate macroeconômico no mainstream norte-americano pós-crise e se o mesmo representou ou não uma ruptura com o programa de pesquisa do NCM, ver Paula e Saraiva (2015).

(6) A política de crédito atua sobre instituições e segmentos específicos do mercado financeiro (interbancário e não bancário), induzindo a mudança na composição do balanço do setor privado, de modo a afetar as condições de financiamento. As operações realizadas pelo BC, que impactam sobre as dívidas privadas e valores mobiliários, alteram o seu balanço e se processa de várias formas, como alterações de colaterais e prazos de maturidade, contraparte em operações monetárias, empréstimos e aquisições de títulos privados. O objetivo principal destas medidas é reduzir as tensões do mercado interbancário, em particular os prazos e spread, bem como melhoria das condições de crédito ao setor não bancário. Ressalta-se que tal política pode gerar efeitos indiretos, na medida em que o mercado em que atua desempenha um papel importante na intermediação financeira. Destaca-se ainda que estas medidas são realizadas diretamente com os intermediários financeiros, o que sugere indiretamente melhorias gerais no mercado, em virtude do papel desempenhado por estas instituições. Porém em mercados específicos, o BC realiza operações de intermediação direta, sem a participação das instituições depositárias, interpondo-se entre investidores e prestatários. 
Ademais, as políticas de quase débito ${ }^{7}$ foram as principais ferramentas de estimulo à retomada do crescimento econômico, e de modo contraditório às proposições teóricas do NCM, implicaram nos efeitos da expansão do balanço do Fed e consequentemente representaram um impacto da base monetária sobre as variáveis reais. Cecioni et al. (2011, p. 6) definem as PMNC:

We therefore classify as non-standard tools all the measures implemented during the global financial crisis that addressed liquidity shortages both of depository institutions and of other important segments of the financial market, the direct purchase of private and public securities, and the adoption of particular forms of communication designed to restore a more normal functioning of the markets and influence expectations about future official interest rates.

No Esquema 1 são apresentados os mecanismos de transmissão da PMNC. Note que as políticas de balanço (crédito e quase débito) se processam por meio da atuação direta do $\mathrm{BC}$ nos mercados financeiros (instituições depositárias e não depositárias), através de compra e/ou troca (temporária e/ou definitiva) de títulos. As políticas de crédito operam via os canais amplo e restrito, sem impactar a estrutura a termo da taxa de juros, com o objetivo de se reestabelecer as condições de liquidez, reduzir os prêmios de risco e incentivar a oferta de crédito. Estas medidas têm como referência teórica os trabalhos de Bernanke e Blinder (1989) e Bernanke (1995).

Já as políticas de quase débito, se fundamentam nas formulações originais de Tobin (1969), Ando e Modigliani (1963) e Modigliani e Sutch (1966). Elas atuam através dos canais de portfólio ( $q$ de Tobin e efeito riqueza) e do "habitat preferido", visando a redução da taxa de juros de longo prazo.

Finalmente, a política de sinalização, se dá por um esforço de aprofundamento da comunicação com o público por parte da autoridade monetária. Assim, o Fed passou a sinalizar de forma mais clara e explícita as suas intenções futuras em relação ao comportamento da taxa de juros e quanto a compra de ativos

(7) As políticas de gestão de quase débito (quasi-debt mangement policy) - compra de títulos do governo e de agências governamentais, bem como a troca de títulos de longo prazo por curto prazo - representam uma intermediação do BC entre o governo e o setor privado. Estas medidas buscam reduzir o prêmio de risco em relação a prazo e liquidez, dos títulos públicos em poder do mercado, promovendo a estabilidade do produto. A sua operacionalização ocorre por meio de compra de títulos públicos, inclusive títulos de agência, pelo BC, podendo ser financiado por meio de variação da base monetária, ou com recursos das reservas bancárias. Ressalta-se que estes ativos são uma importante referência para o mercado, na medida em que correspondem a uma taxa de benchmark (livre de risco) e deste modo, afetam os custos de financiamento e o preço dos ativos em geral. A efetividade desta política de balanço exige, normalmente, um grande volume de compras para que se tenha um efeito sobre o rendimento destes títulos.

(8) A chamada teoria do habitat preferido (preffered habitat), supõe a existência de investidores com preferências heterogêneas e que, portanto se especializam em diferentes classes de ativos. Assim, não se prevê a existência de uma relação estável (ou de uma curva de rendimentos) entre as taxas de juros de curto e de longo prazo - face a inexistência de uma arbitragem perfeita entre as diferentes classes de ativo. 
financeiros (ou eventualmente qualquer outra decisão de PM) ${ }^{9}$. Sua eficácia depende da reputação do Fed e/ou da credibilidade da PM.

\section{Esquema 1}

Mecanismos de Transmissão das Políticas Monetárias Não-convencionais

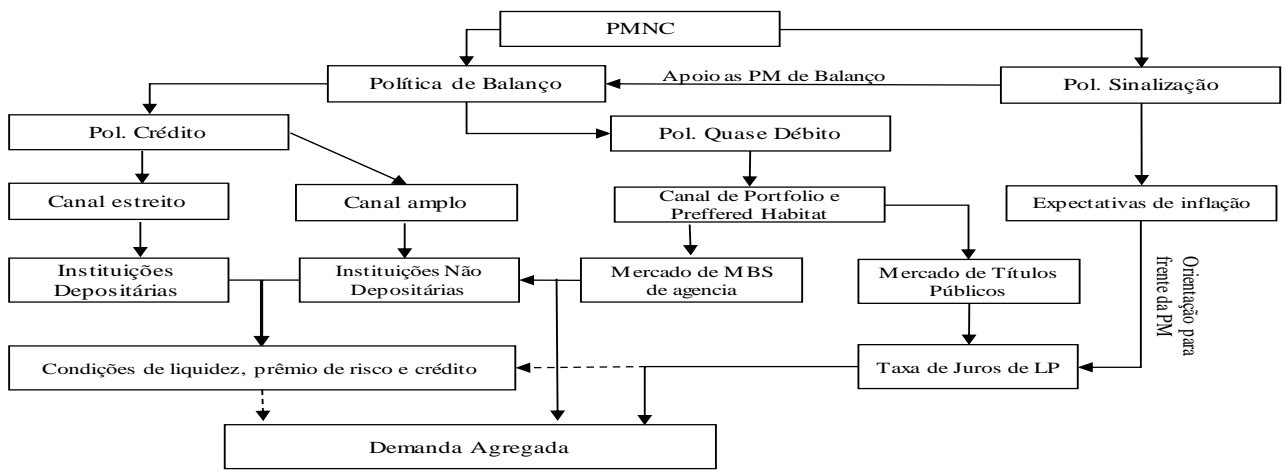

Fonte: Elaboração própria.

\section{Políticas monetárias não-convencionais adotadas nos EUA}

O amplo conjunto de políticas monetárias não-convencionais (PMNC) adotadas nos EUA pode ser subdividido em políticas de crédito e de quase débito. ${ }^{10}$ As políticas de crédito, em um primeiro momento, correspondem ao fornecimento excepcional de liquidez de curto prazo para as instituições depositárias e equivalem, em certa medida, ao papel tradicional do BC enquanto emprestador de última instância, porém tendo como objetivo final, atender também, à instituição e mercados não depositários, num montante muito superior ao auxilio suposto a uma intuição individual. As principais medidas adotadas foram: Term Discount Window Program (TDWP), Term Auction Facility (TAF), Primary Dealer Credit Facility (PDCF) e Term Securities Lending Facility (TSLF), além dos acordos bilaterais de swap cambial - Reciprocal Currency Agreements (RCA) e empréstimos indiretos a instituições não depositárias (Bearn Stearns). De modo complementar, o agravamento da crise em setembro de 2008 exigiu que medidas de provisão de liquidez fossem estendidas diretamente a mutuários e emprestadores nos mercados de crédito, sendo os programas listados a seguir: Commercial Paper Funding Facility (CPFF), Asset-Backed Commercial Paper Money Market Mutual Fund Liquidity Facility (AMLF), Money Market Investor Funding Facility (MMIFF),

(9) Cabe destacar que, desde a popularização do regime metas de inflação (a partir dos anos 1990), verificou-se um esforço de aprimoramento dos canais de comunicação entre o banco central e o público. O que distingue a política de sinalização (em relação ao gerenciamento de expectativas) é a assunção de uma espécie de pré-comprometimento explícito por parte do Fed em relação à trajetória futura dos instrumentos de PM.

(10) Um resumo das medidas e programas adotados pelo Fed a partir de agosto de 2007 é feito no Anexo 1. 


\section{Term Asset-Backed Securities Loan Facility (TALF) e Single-Tranche Term Repurchase Agreements (OMO).}

Neste contexto as políticas de quase débito, foram introduzidas no final de 2008 e buscaram atuar sobre o prêmio de risco e a taxa de juros de longo prazo, almejando a melhoria das condições gerais da economia (produto e emprego). Tais políticas podem ser subdivididas em Large-Scale Asset Purchase Programs (LSAP) e Maturity Extension Program (MEP). Na primeira, o Fed promoveu operações de compra e venda permanente de títulos no mercado aberto, objetivando apoiar os mercados de crédito, particularmente de hipotecas, e reduzir as taxas de juros de longo prazo (para apoiar a atividade econômica e a recuperação dos empregos), por meio da compra de títulos do Tesouro, de títulos de agências (MBS garantidos pela Fannie Mae, Freddie Mac e Ginnie Mae) e de obrigações de agências (Fannie Mae, Freddie Mac e Federal Home Loan Banks). De modo complementar, o MEP representou a troca de títulos do Tesouro de longo prazo por títulos de curto prazo, de modo similar à operação Twist ${ }^{11}$ da década de 1960.

Segundo Taylor (2010a) as PMNC podem ser subdivididas em três períodos distintos. No primeiro período ${ }^{12}$, que compreende os meses de setembro de 2007 a agosto de 2008, foram utilizadas basicamente as políticas de crédito direcionadas as instituições depositárias. Contudo, a intensificação da crise a partir da falência do Lehman Brothers, as dificuldades na AIG e a paralização nos mercados interfinanceiros, em setembro de 2008, marcaram o início da segunda fase da crise financeira americana, na qual se verificou que, além da intensificação e ampliação das políticas de crédito, ocorreu a implantação das políticas de quase débito, que gradativamente foram sendo expandidas, na medida em que as políticas de crédito foram sendo concluídas. A terceira fase, que corresponde ao período de melhoria nas condições financeiras, se estende do segundo semestre de 2009 a dezembro 2013 , quando o Fed anunciou que iria reduzir as compras de ativos e iniciar a reversão das

(11) A “operação twist" foi adotada pelo governo americano (Tesouro e Fed) no período de 1962 a 1964 e representou a ampliação de títulos da dívida pública de curto prazo concomitante à redução dos títulos mais longos. Esta operação buscou simultaneamente elevar a taxa de juros de curto prazo, afetando positivamente o balanço de pagamentos, bem como a redução da taxa de juros de longo prazo, afetando positivamente o investimento empresarial (Greenwood; Vayanos, 2009).

(12) Ressalta-se que o maior montante de recursos nesta fase foi dispendido por meio das políticas de crédito (TDWP, TAF, RCA, TSLF, STOMOP e PDCF) totalizando um montante despendido pelo Fed de US\$ 434 bilhões em julho de 2008. Contudo, no início de março de 2008, o Bear Stearns Companies, Inc. (Bear Stearns) notificou o Fed de que não teria fundos suficientes ou ativos líquidos para cumprir as suas obrigações. Desta forma, o Fed forneceu crédito, no montante de US\$ 12,9 bilhões a taxa de juros de 3,5\% a.a., através de um empréstimo ponte com a JP Morgan Chase Bank (banco depositário), para que a Bearn Stears (banco de Investimento) pudesse cumprir as suas obrigações. No entanto, o empréstimo não foi suficiente para remover as pressões de mercado sobre a empresa, e a sua situação financeira se agravou. Temeroso do impacto da falência da Bearn Stears sobre o mercado financeiro, o Fed autorizou a compra da empresa, em 24 de março de 2008, pelo JP Morgan. No entanto, dada a situação financeira desta e objetivando facilitar o processo de aquisição pela JP Morgan, o Fed criou uma sociedade limitada, denominada de Maiden Lane LLC, que absorveu cerca de US\$ 30 bilhões de ativos da Bearn Stears através de um empréstimo de US\$ 29 bilhões concedidos pelo Fed e mais US\$ 1 bilhão da JP Morgan. Em julho de 2012, o valor do empréstimo foi liquidado e zerado no balanço do Fed. 
políticas de quase débito. A seguir, serão apresentadas as principais características destas políticas.

\subsection{Provisão de liquidez e empréstimos (política de crédito)}

Inicialmente o instrumento clássico de redesconto de liquidez foi alterado pelo Term Discount Window Program (TDWP), que representou o alargamento dos prazos dos empréstimos para as instituições depositárias, flexibilizando a utilização de garantias e aceitação de títulos com vencimentos mais longos, além da redução do spread da taxa de juros cobrada. Em agosto de 2007, o Fed reduziu a taxa de redesconto para 50 p.b. (pontos base) e, em março de 2008, para 25 p.b. acima da meta da taxa dos fundos federais. A partir de fevereiro de 2010, ocorreu uma elevação da taxa primaria de redesconto de 25 p.b., elevando-a para 0,75 p.b., sendo o seu valor mantido até dezembro de 2013.

O montante mensal de empréstimos concedidos pelo Fed, por meio do redesconto, foi muito elevado, principalmente na comparação entre o primeiro período de adoção de PMNC (setembro de 2007 a agosto de 2008) com o segundo semestre de 2008 e ao longo do ano de 2009. Contudo, os novos programas criados pelo Fed, nesta mesma época, tais como o TAF, TSLF, STOMP e PDCF desempenharam uma função similar ao TDWP e tiveram um volume muito superior. Tal fato se deve aos diferenciais em relação à taxa de juros e prazo de vencimento, além de outros fatores que serão discutidos em relação a cada um dos programas. Pode-se observar a partir do gráfico 1 a série histórica da taxa de juros de redesconto, bem como os valores mensais ${ }^{13}$ para o período de dezembro de 2005 a dezembro de 2013. Nota-se claramente uma forte e gradual redução nesta taxa a partir de setembro de 2007 até final de 2008 .

Gráfico 1

Term Discount Window Program (TDWP) - dez./2005 até dez/.2013

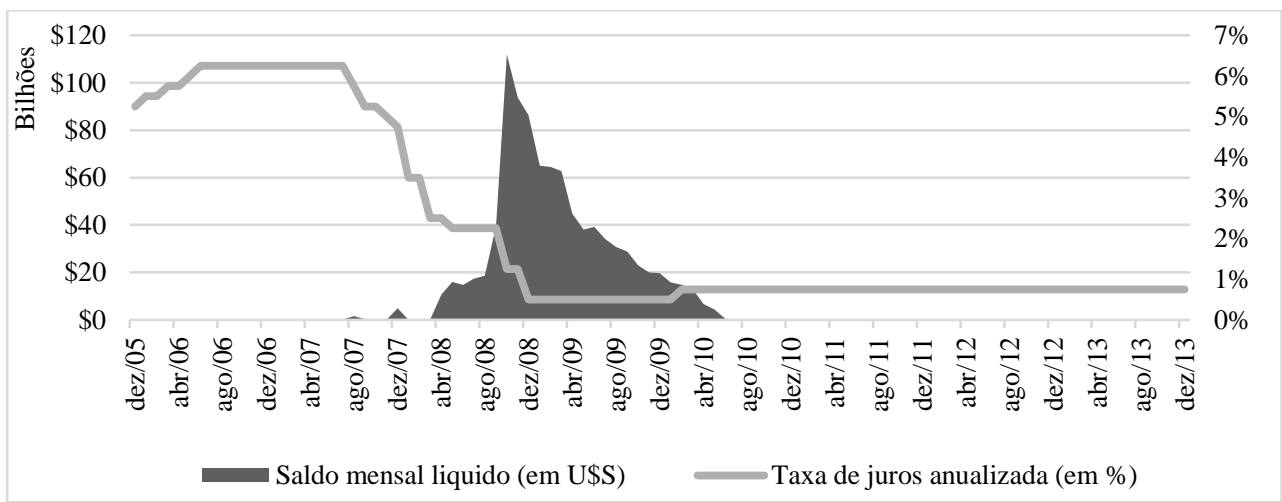

Fonte: Board of Governors of the Federal Reserve System (2014).

(13) Os valores correspondem ao saldo final mensal do balanço do Fed, incorporam os créditos primários, secundários e sazonais. 
Objetivando atender a necessidade de empréstimos das instituições depositárias e promover a distribuição de liquidez nos mercados de financiamento de crédito que operavam sob forte pressão, desde setembro de 2007, foi criado em dezembro deste ano o Term Auction Facility ${ }^{14}$ (TAF). A taxa de juros das operações era definida em leilões competitivos e os prazos de vencimento variavam entre 28 e 84 dias. O TAF se mostrou mais eficiente do que o TDWP em decorrência de dois fatores: i) relutância de diversos bancos em recorrerem ao redesconto, temendo que o empréstimo fosse erroneamente interpretado pelo mercado como um sinal de fraqueza financeira; e ii) as taxas juros cobradas no TAF eram menores do que as taxas de juros do redesconto (Mishkin, 2012, p. 19).

Os leilões de TAF começaram em dezembro de 2007, com montantes de US $\$ 20$ bilhões e prazo de 28 dias, mas devido ao acirramento da crise, em outubro de 2008, o montante foi elevado para valores acima de US\$ 400 bilhões e os prazos estendidos para 84 dias, atingindo valores superiores a US\$ 600 bilhões após a quebra do Lehman Brothers, concomitante a uma acentuada queda na taxa de juros, vindo tais valores a reduzir ao longo de 2009. Ressalta-se que em março de 2010 o programa foi encerrado. Os saldos mensais líquidos e as taxas de juros anualizadas são reportados no Gráfico 2.

\section{Gráfico 2}

Term Auction Facility (TAF) - dez./2009 a mar./2010

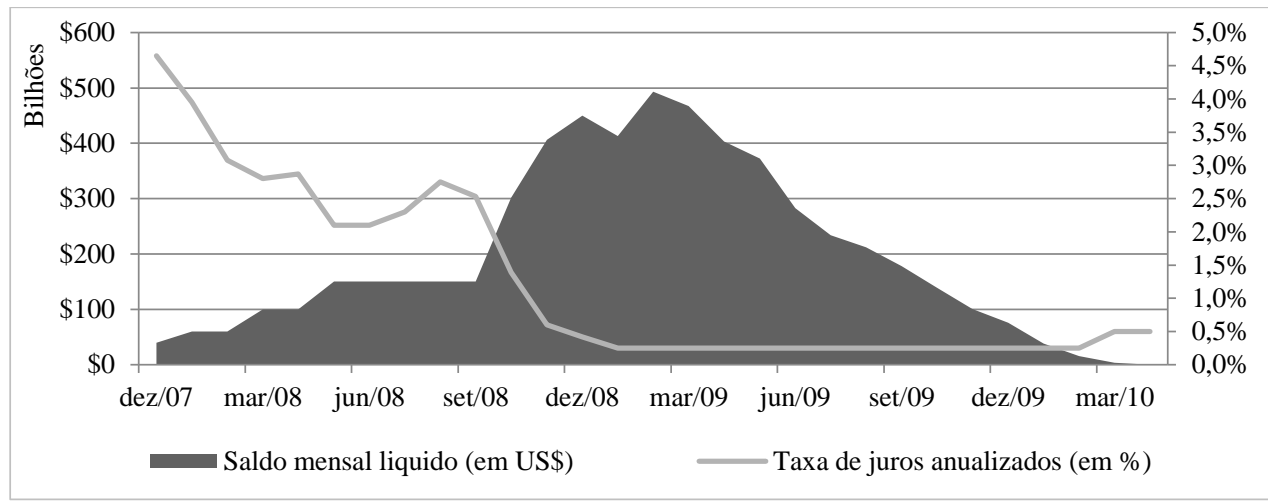

Fonte: Board of Governors of the Federal Reserve System (2014).

Ademais, a crise sistêmica na economia americana promoveu um efeito contágio que impactou sobremaneira a economia internacional, promovendo forte movimento de fluxos de capitais e volatilidade na taxa de câmbio em diversos países. Como decorrência, foram realizados contratos de swap entre o FED e Bancos

(14) O TAF representou um objetivo similar e garantias idênticas ao TDWP, com leilões de fundos de longo prazo, porém sem o estigma associado a este (títulos do tesouro de curto prazo), permitindo a utilização de garantias relativas à fundos longos. 
Centrais desses países ${ }^{15}$, denominados de Reciprocal Currency Agreements (RCA). Este representou o fornecimento excepcional de liquidez (em dólares) aos bancos centrais estrangeiros para que estes pudessem prover liquidez em moeda americana nos seus respectivos mercados domésticos. O volume mais intenso de contratos ocorreu após a quebra do Lehman Brothers, alcançando valores superiores a US $\$ 500$ bilhões de dólares no ápice do contagio da crise, entre outubro e dezembro de 2008, conforme mostra o Gráfico 3.

Gráfico 3

Reciprocal Currency Agreements (RCA) - dez./2007 a out./2010

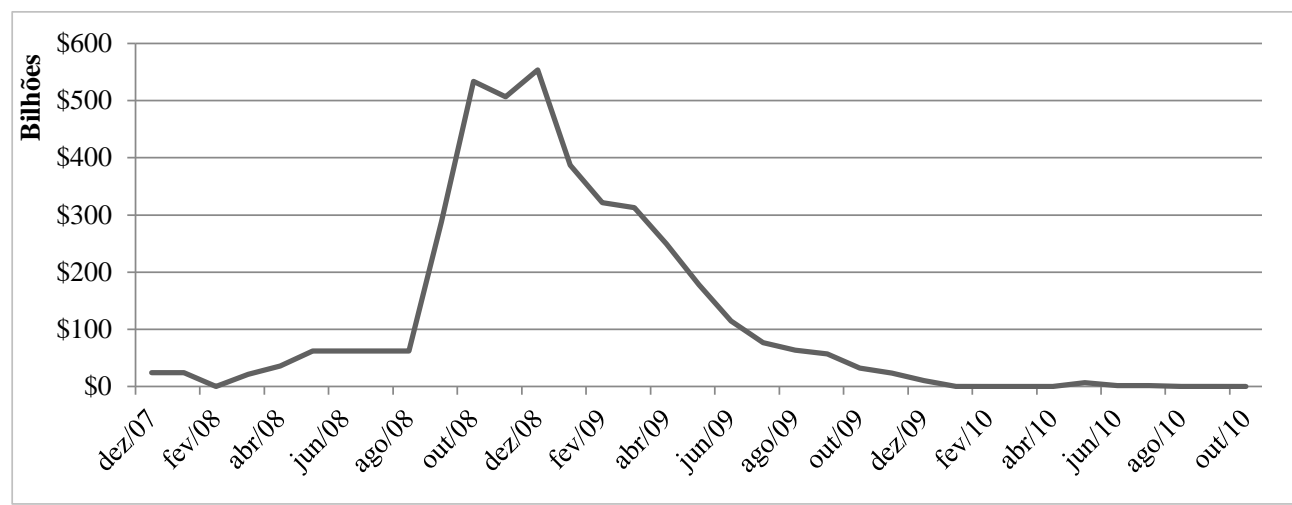

Fonte: Board of Governors of the Federal Reserve System, 2014.

No início do primeiro semestre de 2008, os dealers primários tiveram dificuldades em obter financiamento a prazo (período superior a um dia) e fornecer garantias em virtude dos mercados monetários terem se tornados ilíquidos. Neste contexto, o Fed lançou o Term Securities Lending Facility (TSLF), permitindo o empréstimo de títulos do Tesouro mais líquidos (curto prazo), por meio de leilões competitivos, com o aceite de um amplo conjunto de títulos menos líquidos como colateral $^{16}$. Adicionalmente o Fed criou o TSLF Options Program (TSLF-OP), de modo similar ao TSLF, porém promovendo liquidez adicional para os dealers primários nos períodos de elevada pressão nos mercados de garantias, com a disponibilização de títulos do Tesouro, permitindo a estas instituições acessá-los caso necessário. Observa-se que os empréstimos de títulos alcançaram valores superiores a US\$ 150 bilhões ao longo do segundo semestre de 2008, bem como as taxas de juros $^{17}$ tiveram forte volatilidade alcançando, em determinados períodos, valores superiores a $3 \%$ a.a.

(15) Banco do México, Banco da Inglaterra, Banco do Japão, Banco da Dinamarca, Banco Central Europeu, Banco Central da Austrália, e Banco Central da Suíça, Banco Central do Brasil, Banco da Coréia do Sul, Banco da Noruega, Autoridade Monetária de Singapura e Banco da Suécia.

(16) O colateral aceito pelo Fed nestas operações compreendia os títulos do Tesouro menos líquidos, títulos de agências e títulos de hipotecas.

(17) A taxa de juros anualizada cobrada pelo Fed teve como referência o valor de mercado de títulos do Tesouro emprestado. 


\section{Gráfico 4}

Term Securities Lending Facility (TSLF) - mar./2008 a jul./2009

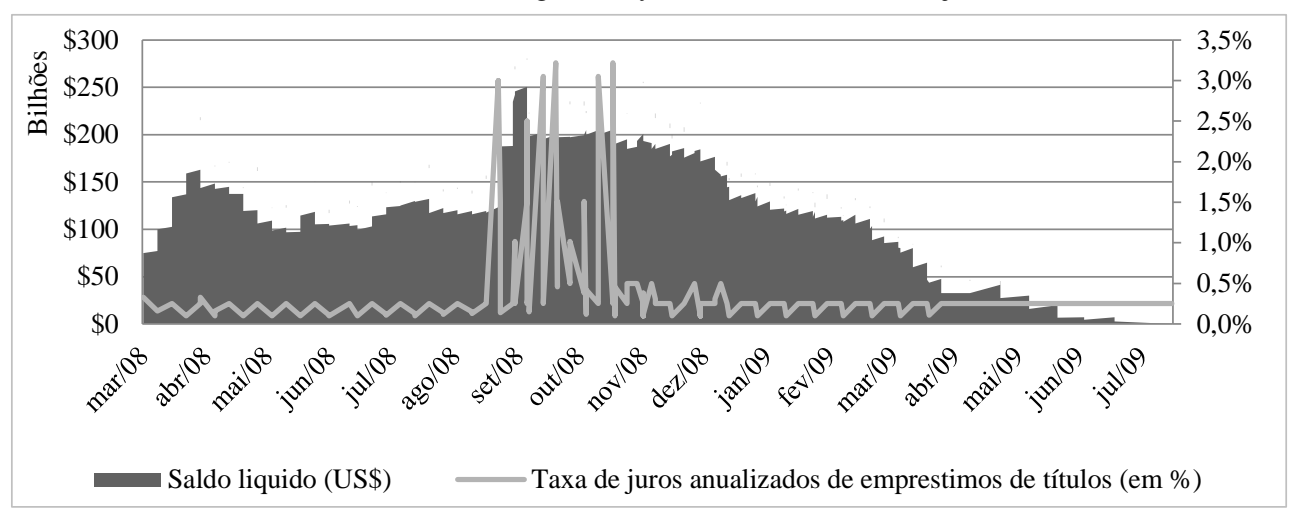

Fonte: Board of Governors of the Federal Reserve System (2014).

Objetivando ainda reduzir o elevado estresse nos mercados financeiros e em particular o problema de liquidez em diversos segmentos, o Fed criou o Single Tranche OMO Program (STOMOP), em março de 2008, ofertando fundos de emergência a dealers primários, através de leilões com acordo de recompra (prazo de 28 dias), com contrapartida de títulos que normalmente são aceitos nas operações regulares de mercado aberto. O saldo médio destas operações, ao longo do período de abril de 2008 até janeiro de 2010, oscilou entre US\$ 80 e US\$ 100 bilhões, ao passo que as taxas de juros tiveram acentuada tendência de queda a partir de outubro de 2008, conforme pode ser visto no Gráfico 5.

\section{Gráfico 5}

Single Tranche OMO Program (STOMOP) - mar./2008 a jan./2009

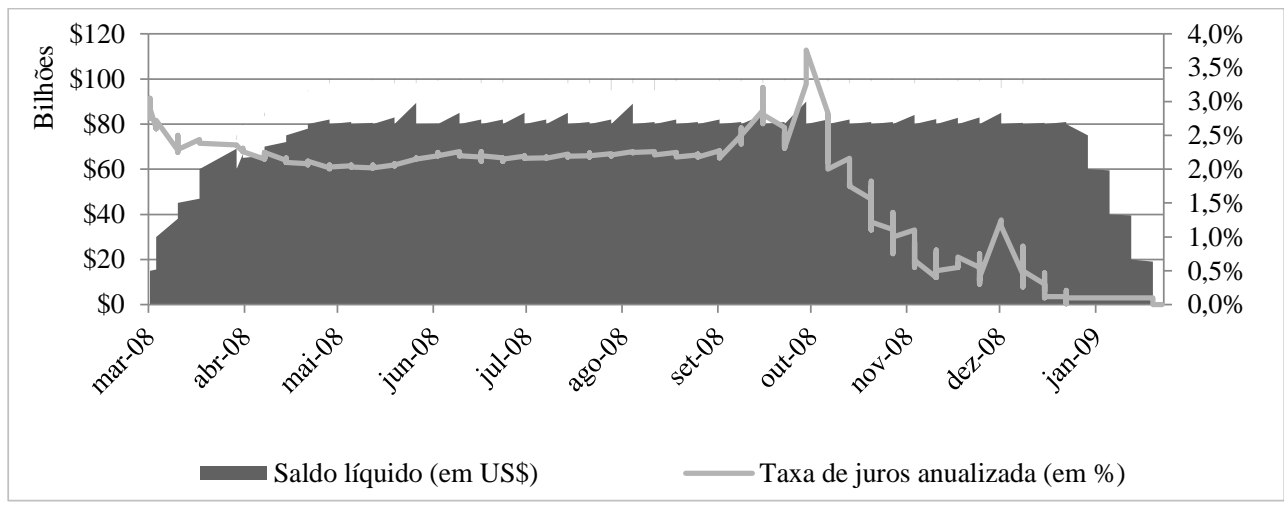

Fonte: Board of Governors of the Federal Reserve System (2014).

As operações de mercado aberto realizadas pelo Fed, em períodos de funcionamento normal de mercados, são executadas com o apoio dos dealers primários que desempenham um papel importante na transmissão da política 
monetária. No entanto, em uma conjuntura de forte ruptura financeira, como observada na crise de 2008, a paralisação deste mercado tem impacto negativo sobre a oferta de crédito e na atividade econômica. Objetivando melhorar o funcionamento do mercado interbancário, o Primary Dealers Credit Facility (PDCF) foi criado para aumentar a capacidade dos dealers em fornecerem financiamento aos participantes do mercado, bem como promover, de um modo geral, a melhoria no funcionamento do mercado financeiro. Este programa operou de forma similar ao redesconto, facilitando as operações de overnight. A sua operacionalização foi importante no primeiro semestre de 2008, e sobremaneira no segundo semestre, atingindo valores próximos a US\$ 50 bilhões em um único dia, ao longo do mês de setembro, conforme mostra o Gráfico 6.

\section{Gráfico 6}

Primary Dealers Credit Facility (PDCF) - mar./2008 a maio/2009

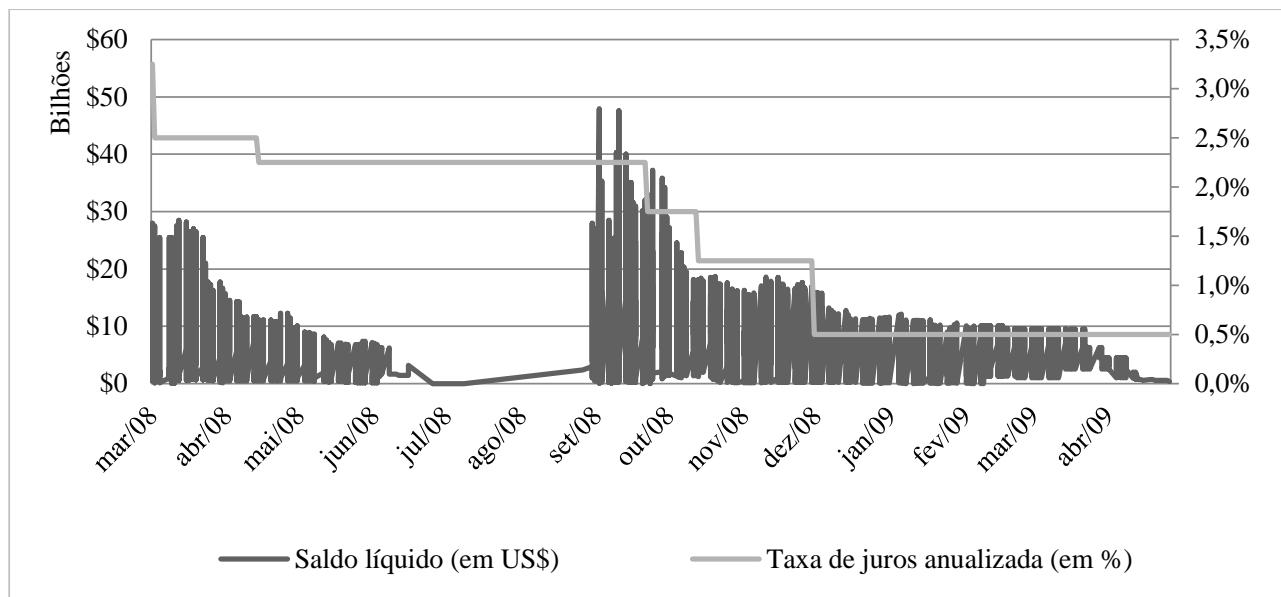

Fonte: Board of Governors of the Federal Reserve System (2014).

Ressalta-se que, além das operações com dealers e instituições depositárias, o Fed concedeu empréstimos diretamente para mercados específicos, além de instituições não bancárias, de modo a mitigar possíveis efeitos sistêmicos sobre o sistema financeiro norte-americano, bem como minimizar os impactos sobre a atividade econômica. Dentre as diversas ações e programas, destacaram-se o fornecimento de recursos para aquisição de Commercial Paper (CP), Mortgage Backed Securities (MBS) e Asset Backed Securities (ABS), bem como concessão de crédito para a JP Morgan adquirir a Bearn Stears e para a American Internacional Group (AIG), de modo a evitar a sua falência (Mishkin, 2012, p. 19). Ademais, concedeu empréstimos ao Bank of America e ao Citigroup. A seguir são descritas, brevemente, as principais medidas de apoio a instituições financeiras (ADIF) por meio de empréstimos diretos e indiretos do Fed, Tesouro e Federal Deposit Insurance Corporation (FDIC). 
No Gráfico 7 são apresentados os saldos dos valores concedidos pelo Fed, Tesouro americano e FDIC para instituições financeiras específicas que tiveram apoio direto destes órgãos, como foi o caso da AIG em setembro de 2008, além da criação e capitalização das unidades de negócios, como o Maiden Lane LLC I que apoiou a JP Morgan na compra do Bearn Stearns e o Maiden Lane LCC II e III que concedeu auxílio ao AIG, a partir de novembro deste ano. O objetivo de tais operações era evitar o risco de contágio, já que tais instituições eram consideradas "too big to fail", tendo em vista que AIG e Bear Sterns eram vistas como relevantes nos mercados em que atuavam. $\mathrm{O}$ apoio total direto a instituições financeiras ultrapassou o montante de US\$ 100 bilhões ao longo do período de outubro de 2008 a janeiro de 2011. Só o valor total da ajuda à AIG atingiu o volume de US\$ 90 bilhões em outubro de 2008. Ressalta-se que os valores são apresentados até dezembro de 2013, quando o valor residual dos empréstimos, a exceção do Maiden Lane LLC I finalizado em janeiro de 2011, equivaliam ao montante de US\$ 1,6 bilhões.

\section{Gráfico 7}

Apoio direto a instituições financeiras (ADIF) - jul./2008 a dez./2013

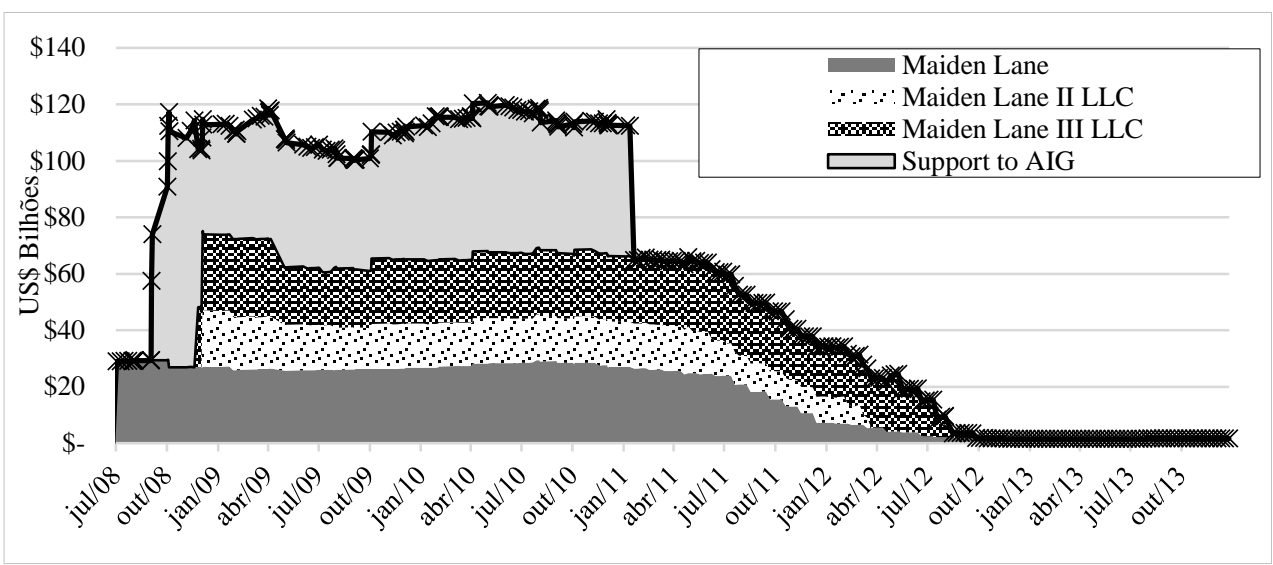

Fonte: Board of Governors of the Federal Reserve System (2014).

As políticas de crédito descritas até o momento foram implantadas pelo Fed, Tesouro e FDIC, e inicialmente objetivaram conter os impactos da primeira fase da crise (segundo semestre de 2007 e o primeiro semestre de 2008) sobre a liquidez das instituições financeiras e promover o reestabelecimento dos mercados de crédito. Neste ponto, deve-se ressaltar que a intensidade destas políticas foi sendo gradativamente reduzida ao longo primeiro semestre de $2008^{18}$. No entanto, a falência do Lehman Brothers em setembro de 2008 provocou uma piora substancial no sistema financeiro norte-americano, exigindo a ampliação das medidas de

(18) O montante de estímulos via políticas de crédito alcançou o seu ápice em julho de 2008 com U\$S 462,88 bilhões, reduzindo para U\$S 455,71 bilhões em agosto. Ademais, tal afirmação é compartilhada por Mishkin (2011, p. 22-23) que identifica a avaliação positiva do Fed ao longo do primeiro semestre, ainda que parcial, de que as medidas adotadas (políticas de crédito) estavam tendo efetividade, o vale da crise havia passado e a economia começava a se recuperar. 
liquidez e empréstimos do Fed que estavam em andamento (TDWP, TAF, RCA, TSLF, STOMOP, PDCF e ADIF) e redução da taxa básica de juros para valores próximos a zero (entre 0 e $0,25 \%$ a.a.), cujo patamar é equivalente apenas à década de 1930. Ademais foi necessária a adoção de um novo conjunto de medidas, em particular que abarcassem também uma parcela do sistema financeiro não-bancário que não estava sobre o guarda-chuva da autoridade monetária e das suas linhas de liquidez e de empréstimos. As principais medidas foram Money Market Fund Liquidity Facility (AMLF), Commercial Paper Funding Facility (CPFF) e AssetBacked Securities Loan Facility (TALF).

O agravamento da crise em setembro de 2008 desencadeou um volume expressivo de resgates dos Money Market Mutual Funds ${ }^{19}$ (MMMFs), obrigando os gestores destes fundos a venda de ativos em mercados iliquidos, o que provocaria perda substancial nos preços e no valor destes e consequentemente do mercado de curto prazo. De fato, tais fundos tiveram uma elevada procura por resgate, ao mesmo tempo em que os preços de seus ativos despencaram no mercado e o spread aumentou (300 para 400 p.b.). De modo a evitar a quebra destes fundos, pois estes não tinham acesso a janela de redesconto das instituições depositárias e nem ao amplo conjunto de políticas de crédito que vinham sendo implantadas, o Fed lançou um instrumento específico para o mercado de ABCP. O Asset Backed Paper Money Market Fund Liquidity Facility Comercial (AMLF) ampliou a liquidez no mercado para Asset Backed Commercial Paper (ABCP), através do fornecimento de crédito para as instituições depositárias, holdings bancárias, dentre outras, que utilizaram os recursos para a compra de ABCP. Observa-se que o AMLF realizou nos primeiros dez dias de operação empréstimos no montante de US\$ 150 bilhões (Duygan-Bump et al., 2010; ver, ainda, o Gráfico 8).

\section{Gráfico 8}

Asset-Backed Paper Money Market Mutual Fund Liquidity Facility Commercial (AMLF) set./2008 a out./2009

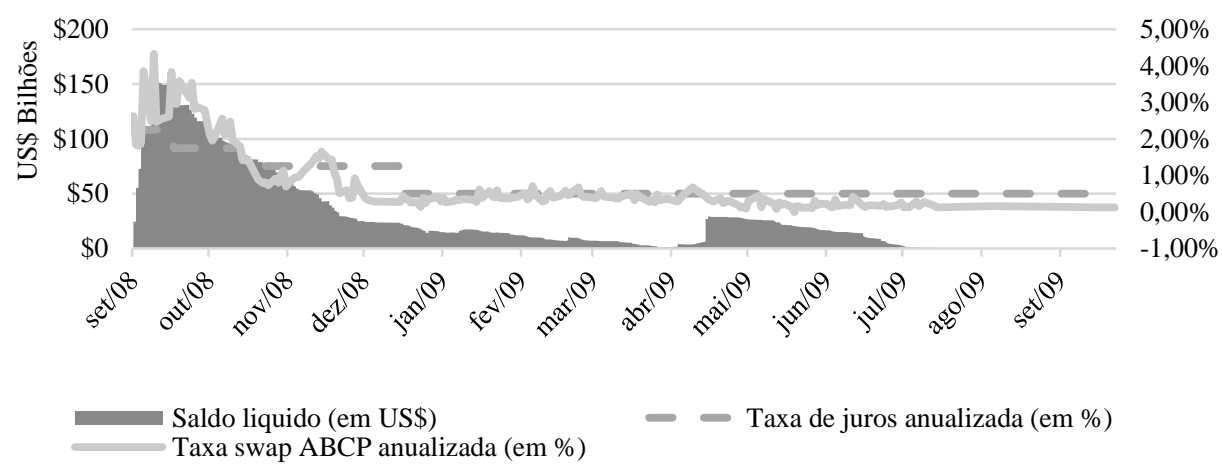

Fonte: Board of Governors of the Federal Reserve System (2014).

(19) Tais fundos envolvem trilhões de dólares e os investidores são famílias, fundos de pensão, municípios e empresas. 
Os problemas enfrentados pelos MMMF em virtude da relutância de investidores em adquirirem Commercial Paper provocou uma elevação das taxas de longo prazo destes papéis e a necessidade, por parte das firmas, de refinanciamento diário dos títulos emitidos, dificultado sobremaneira o financiamento empresarial de curto prazo. Deste modo, o Fed lançou o Commercial Paper Funding Facility (CPFF), que operava de modo similar ao AMLF, porém objetivando promover a liquidez destes títulos, além de alongar os prazos de vencimento. Para tanto, foi criada uma empresa de responsabilidade limitada (CPFF LLC) que utilizou os fundos emprestados pelo Fed para a compra direta destes papéis de emissores elegíveis, melhorando a liquidez deste mercado. Dois tipos de ativos foram objeto de compra, no primeiro o Asset-Backed Commercial Paper (ABCP) teve taxa média de juros em torno de 3,35\% a.a., enquanto que o segundo, o Commercial Paper (CP) teve taxa média de 1,34\% a.a. No que se refere ao prazo de vencimento dos empréstimos, este foi estabelecido para 90 dias. No Gráfico 9 os valores agregados destes dois ativos são apresentados, podendo ser observado o forte crescimento dessas operações até inicio de 2009, atingindo mais de US\$ 300 bilhões, vindo a reduzir gradualmente ao longo do ano até atingir valores residuais ao final do ano.

Gráfico 9

Commercial Paper Funding Facility (CPFF) - out/2008 a abr/2010

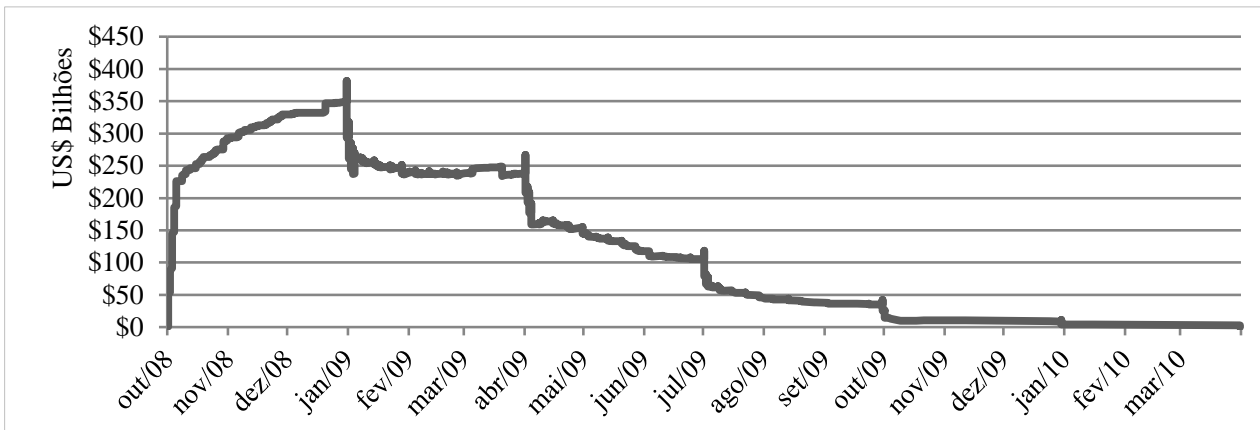

Fonte: Board of Governors of the Federal Reserve System (2014).

A segunda fase da crise financeira, a partir de setembro de 2008, provocou uma queda ainda maior no mercado de crédito, em particular o mercado de AssetBacked Securities (ABS), reduzindo significativamente a oferta de crédito para familias e empresas. Desta forma, o Fed em parceria com o Tesouro lançou o AssetBacked Securities Term Loan Facility (TALF). Com este programa o Fed forneceu empréstimos de longo prazo (3 a 5 anos) para a compra de recém-emitidas triple- $A$ nominal ABS direcionadas para o crédito ao consumidor e empréstimos para pequenas empresas. Este programa foi expandido para incluir empréstimos relacionados aos títulos lastreados em hipotecas comerciais (CMBS) (Cecioni et al., 
2011). Como pode ser visto no Gráfico 10 os valores deste programa cresceram acentuadamente de março de 2009 a abril de 2010, quando atingiu um patamar de cerca de US\$ 70 bilhões, vindo a diminuir apenas a partir de abril de 2012, como resultado da melhora no mercado de ABS.

Gráfico 10

Asset-Backed Securities Term Loan Facility (TALF) - mar/2009 a mar/2015

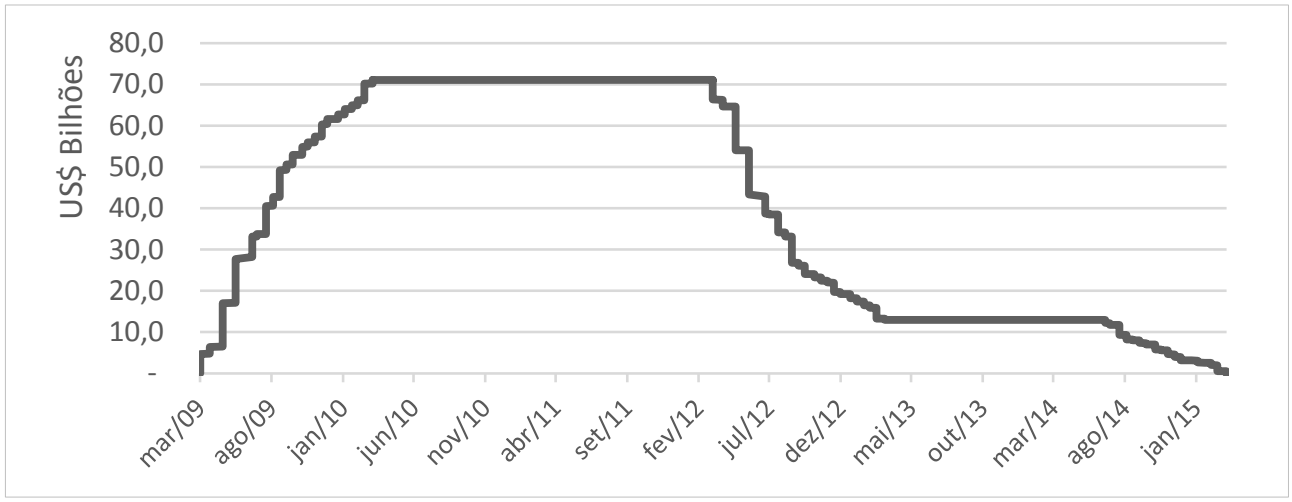

Fonte: Board of Governors of the Federal Reserve System, 2014.

O Gráfico 11 mostra a evolução do montante agregado das políticas de crédito adotadas pelo Fed no periodo de setembro de 2007 a dezembro de 2013. Na primeira fase da crise, as medidas tomadas (TDWP, TAF, RCA, TSLF, STOMOP e PDCF) alcançaram, em agosto de 2008, um montante de US\$ 455 bilhões.

Gráfico 11

Montante total das políticas de crédito - jan./2007 a dez./2013

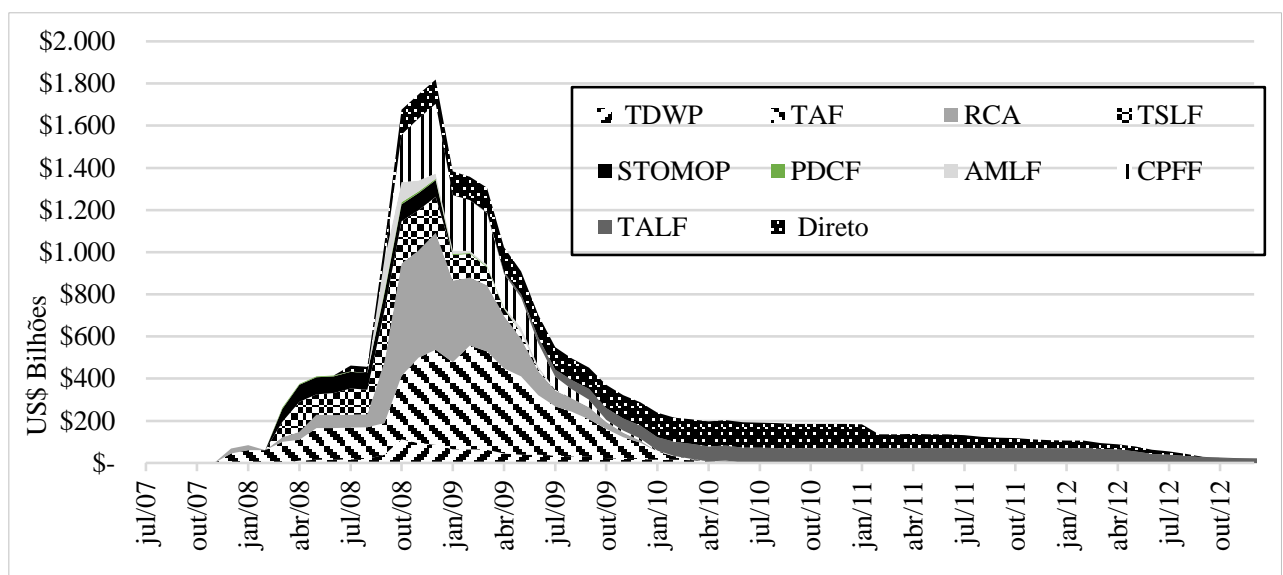

Fonte: Elaboração própria a partir do Board of Governors of the Federal Reserve System (2014). 
Contudo, o agravamento da crise em setembro de 2008 exigiu uma ampliação destas politicas de crédito, além da introdução de novas medidas (AMLF, CPFF e TALF), atingindo US\$ 1 trilhões neste mês e US\$ 1,8 trilhão em dezembro do mesmo ano. Nesta segunda fase o volume de empréstimos permaneceu elevado até o final de 2009. A partir do primeiro semestre de 2010, boa parte destas politicas foram concluidas, sendo que em abril de 2010 apenas a TALF permaneceu ativa e o volume de incentivos caiu para US\$ 78 bilhões.

No entanto, a redução das politicas de crédito não representou uma redução da intervenção direta do Fed sobre o mercado financeiro e as medidas de estimulo à economia americana. No final do segundo semestre de 2008 um novo conjunto de politicas não-convencionais foi implantado. As politicas de quase débito objetivaram lidar com a perda da capacidade da PM afetar a atividade econômica, em virtude da taxa básica de juros ter alcançado o limite inferior próximo a zero a partir de dezembro de 2008.

\subsection{Compra de ativos em larga escala}

Um segundo conjunto de medidas não convencionais foi a realização de operações de mercado aberto, que de modo diferente ao programa STOMOP, promoveu a compra definitiva de títulos públicos de longo prazo. Segundo Blinder (2010), estas compras de ativos almejaram reduzir a inclinação da curva de rendimentos, bem como atuar sobre os spreads ${ }^{20}$ de ativos (margem de risco e/ou liquidez), promovendo uma redução das taxas de juros mais longas e, consequentemente, estimulando o produto e o emprego, por meio do impacto positivo sobre as condições financeiras mais gerais e particularmente nos mercados específicos, como os hipotecários. Estas políticas de quase débito envolveram dois programas, Large-Scale Asset Purchase Programs (LSAP) e Maturity Extension Program (MEP). Ressalta-se que o LSAP promoveu uma expansão substancial do balanço do Fed, ao passo que o MAP alterou a maturidade dos títulos públicos detidos pelo Fed.

No primeiro (LSAP), o Fed realizou a compra de títulos do Tesouro, de obrigações de agências públicas (Fannie Mae, Freddie Mac, e Federal Home Loan Banks), além da aquisição de Mortgage-Backed Securities (MBS), títulos estes garantidos também por agências públicas (Fannie Mae, Freddie Mac e Ginnie Mae). O segundo programa (MEP) promoveu a compra de títulos do Tesouro com vencimentos mais longos (6 a 30 anos), detidos pelo mercado, em troca de títulos públicos com prazo de vencimento mais curto (igual ou inferior a 3 anos). Ressalta-

(20) Conforme abordado por Blinder (2010, p. 4), os títulos públicos livres de risco (risk free) são a referência para o spread cobrado sobre os demais títulos, sendo este composto por uma parcela relativa a liquidez e a outra relacionada a prêmio de risco. 
se que estes programas foram identificados com quantitative easing ${ }^{21}$ e executados em três momentos. No Gráfico 12, observa-se o impacto das compras e trocas de ativos sobre o balanço do Fed, desagregados por MBS, dívida de agências governamentais e títulos públicos, para o período de agosto de 2007 a outubro de 2014, quando o programa foi finalizado. Na sequência, cada uma das quatro rodadas de quantitative easing $(\mathrm{QE})$ são analisadas.

Gráfico 12

Large-Scale Asset Purchase Programs (LSAP) - jan./2007 a dez./2014

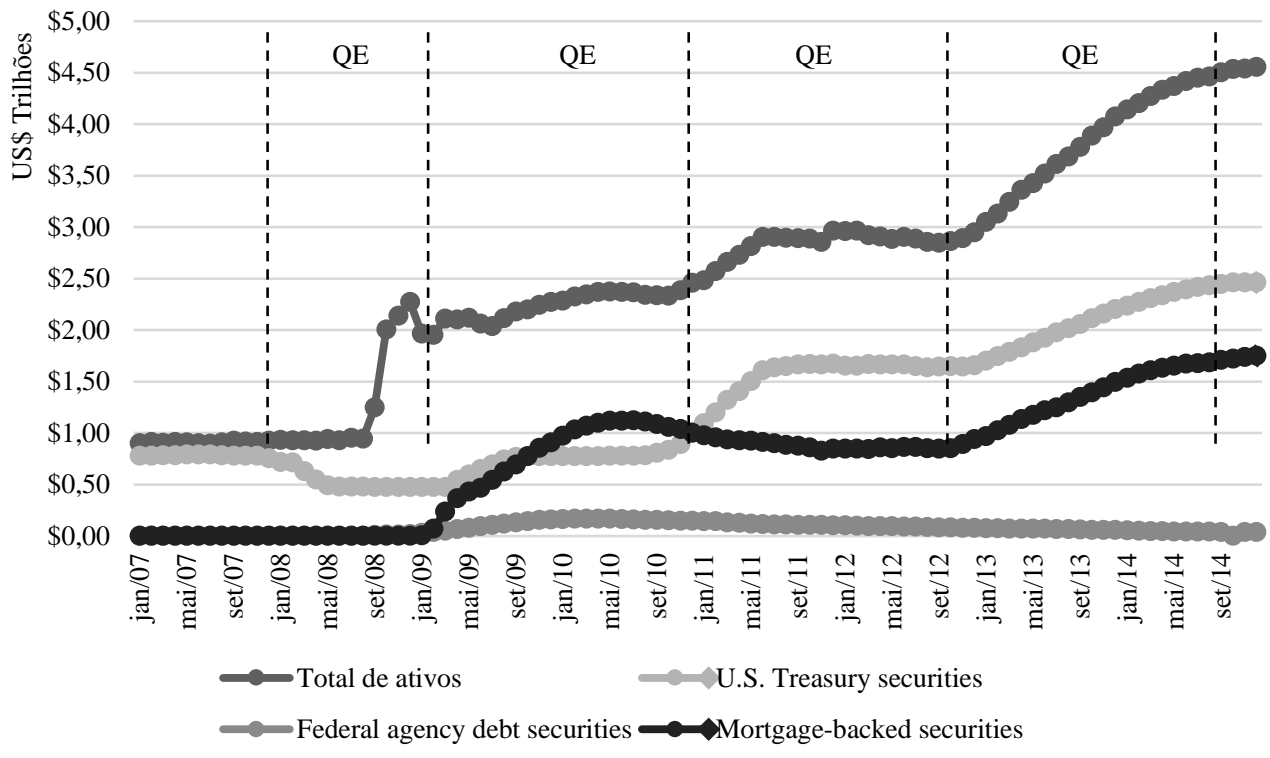

Fonte: Elaboração própria a partir do Board of Governors of the Federal Reserve System (2014).

Deve-se ressaltar que, antes de entrar na discussão acerca do que ficou identificado como "quantitative easing" $(\mathrm{QE})$, as primeiras políticas de quase débito (aqui nominadas de QE 0) ocorreram inicialmente em relação ao lado do ativo e do passivo do Fed. No início de 2008, este iniciou a troca de títulos do Tesouro de curto prazo (T-Bill) por outros ativos menos líquidos. Em janeiro de 2008 (Gráfico 12), o Fed detinha cerca de US\$ 718 bilhões em títulos do governo, passando a US\$ 475 bilhões em dezembro do mesmo ano. Ressalta-se que nesta política do lado do ativo, o objetivo era reduzir o prêmio de liquidez e, deste modo, promover a melhora na liquidez dos mercados financeiros. Em um segundo momento a expansão do balanço do Fed ocorreu em relação ao lado do passivo e, como destacado por Taylor (2010b), estas duas medidas foram implementadas antes mesmo de que a taxa básica de juros

(21) Segundo Blinder (2010, p. 2), o “quantitative easing” pode ser definido como a mudança na composição, maturidade e/ou tamanho do balanço de um BC e normalmente são orientadas para a melhoria da liquidez e condições de crédito de mercado. 
atingisse o limite inferior igual a zero (em outubro de 2008). Segundo Blinder (2010, p. 7-8):

The second sort of early QE operations began on the liabilities side of the Fed's balance sheet. To assist the Fed, the Treasury started borrowing in advance of its needs (which were not yet as ample as they would become later) and depositing the excess funds in its accounts at the central bank. While these were fiscal operations, they enabled the Fed to increase its assets-by purchasing more securities and making more discount window loans (e.g., through TAF, the Term Auction Facility) - without increasing bank reserves (...). That's very helpful to a central bank that is a bit timid about stimulating aggregate demand and/or is worried about running out of T-bills to sell, both of which were probably true of the Fed then. But notice that these operations marked the first breaching - however minor - of the wall between fiscal and monetary policy. In addition, the Fed began lending to primary dealers in the immediate aftermath of the Bear Stearns rescue. Then came the failure of Lehman Brothers, and everything changed, including the Fed's monetary policy.

No final de 2008, o Fed lançou o LSAP (Quantitative Easing I-QE I). Em novembro deste mesmo ano, objetivando estimular o mercado hipotecário e reduzir as taxas de juros de longo prazo dos empréstimos do setor imobiliário, foi criado o Government Sponsored Entities Purchase Program (GSEPP), na qual o Fed anunciou a compra de US\$ 175 bilhões em títulos de dívidas de agências e, a partir de janeiro de 2009, a aquisição de um total de US\$ 1,25 trilhões de Mortgage Backed Securities (MBS). Destaca-se que as compras de títulos e de dívidas foram programadas e concluídas em agosto de 2010 (Cecioni et al., 2012, p. 13).

Ademais, em decorrência das preocupações com as condições dos mercados de créditos o Fed lançou o Purchases of Long-Term Treasuries, que resultou na compra de US\$ 300 bilhões em títulos de longo prazo do Tesouro norte-americano ao longo dos meses de março a outubro de 2009. Neste ponto deve-se ressaltar que as operações de mercado aberto do Fed, que promoveram a compra definitiva de títulos de agência e do Tesouro, repercutiram em uma substancial expansão do balanço do Fed, que saltou de US\$ 900 bilhões em títulos detidos em setembro de 2007 para US\$ 2 trilhões em novembro de 2010. O Gráfico 13 mostra o que foi denominado de QE I, com a evolução do montante de compras de títulos do Tesouro, MBS e dívida de agências, bem como o seu impacto sobre a expansão do balanço do Fed.

Contudo, uma vez que a tendência de retomada do crescimento econômico nos EUA permanecia lenta no ano de 2010, em novembro de 2010 foi lançado o "Quantitative Easing II" (QE II). Esta segunda compra de ativos buscou apoiar a recuperação da atividade econômica por meio de estímulos aos gastos das famílias e 
empresas, e representou uma nova rodada de compras de títulos de longo prazo do Tesouro americano, no montante de US\$ 600 bilhões (Cecioni et al., 2012, p. 14). Em novembro de 2010, a detenção de títulos públicos na carteira do Fed era de cerca de US\$ 1,04 trilhões e atingiu o montante de US\$ 1,65 trilhões a partir de junho de 2011. O impacto da compra de títulos públicos promovidos que QE II sobre o total de ativos do Fed ampliou a participação destes títulos no total dos ativos em 15 p.p. e alcançando cerca de $56 \%$.

Deve-se ressaltar ainda que, em setembro de 2011, o Fed lançou uma variante do programa de compra de títulos, denominada Maturity Extension Program $^{22}$ (MEP), objetivando apoiar as medidas de redução as taxas de juros de longo prazo $^{23}$, trocando cerca de US\$ 667 bilhões de títulos de longo prazo do Tesouro americano de sua carteira, com maturidade de 6 a 30 anos, pelo equivalente em títulos do Tesouro de curto prazo, com vencimento de 3 anos ou menos. Tal medida teve como objetivo reduzir as taxas de juros de longo prazo e deste modo promover melhorias nas condições de financiamento da economia, tendo sido concluído em dezembro de 2012. Destaca-se que a proposição inicial foi a compra de US\$ 400 bilhões em títulos, porém esta foi ampliada, em junho de 2010 para mais US\$ 267 bilhões.

Posteriormente, em setembro de 2012, foi lançado o "Quantitative Easing III” (QE III), objetivando inicialmente a aquisição de cerca de US\$ 40 bilhões de MBS por mês. Ademais, a partir de janeiro de 2013, com a finalização do MEP, o Fed instituiu a compra mensal de US\$ 45 bilhões de títulos de longo prazo do Tesouro (Mishkin, 2012; Bernanke, 2012a). Estas compras foram realizadas ao longo de todo o ano de 2013, sendo que o Fed anunciou, em dezembro de 2013, que iniciaria a redução da compra de títulos mensais, a partir de 2014. No gráfico 13, pode-se observar o impacto das compras mensais de títulos públicos e MBS sobre os ativos totais do Fed, ficando claro que essas foram as operações que mais impactaram no balanço do Fed.

Deve-se registrar que as três rodadas de "Quantitative Easing" promoveram ao longo do período de novembro de 2008 a dezembro de 2013 uma expansão sem precedentes no balanço do Fed. Este aumento, que se iniciou durante o auge das políticas de crédito, além de suprirem a redução destas medidas ${ }^{24}$, promoveu uma ampliação dos ativos totais detidos pelo Fed de US\$2,1 trilhões para cerca de US\$

(22) Este programa foi também identificado como "operação twister".

(23) Segundo Bernanke (2012b, p. 6), "By reducing the average maturity of the securities held by the public, the MEP puts additional downward pressure on longer-term interest rates and further eases overall financial conditions".

(24) As políticas de crédito, também denominadas de "credit easing", atingiram o montante de US\$1,8 trilhões em dezembro de 2008, ao passo que em julho de 2009 haviam caído para menos de US\$ 500 bilhões e em dezembro de 2013 representavam cerca de US\$ 15 bilhões. 
4,1 trilhões durante o período acima referido. Como resultado mais geral, promoveram uma expansão da base monetária que resultou, em grande medida, no aumento das reservas voluntárias das instituições depositárias no Fed.

Finalmente ressalta-se que, ao longo do período de 2007 a 2013, o Fed ampliou significativamente o seu balanço em mais de US\$ 3,2 trilhão, por meio de um amplo conjunto de programas de intervenção direta nos mercados financeiros. As políticas de crédito foram as principais medidas adotadas ao longo dos anos de 2007, 2008 e até meados de 2009. A partir de 2009, as políticas de quase débito se tornaram o principal instrumento de atuação. Este conjunto de PMNC é sintetizado no Anexo 1, onde é apresentado o impacto financeiro (em valores), desagregado e total das políticas de crédito e quase débito sobre o balanço do Fed. O Gráfico 13 mostra o saldo mensal do montante de cada uma das operações de mercado que foram implementadas, além da evolução do ativo total do Fed.

Gráfico 13

Impacto das políticas monetárias não-convencionais sobre o balanço do Fed

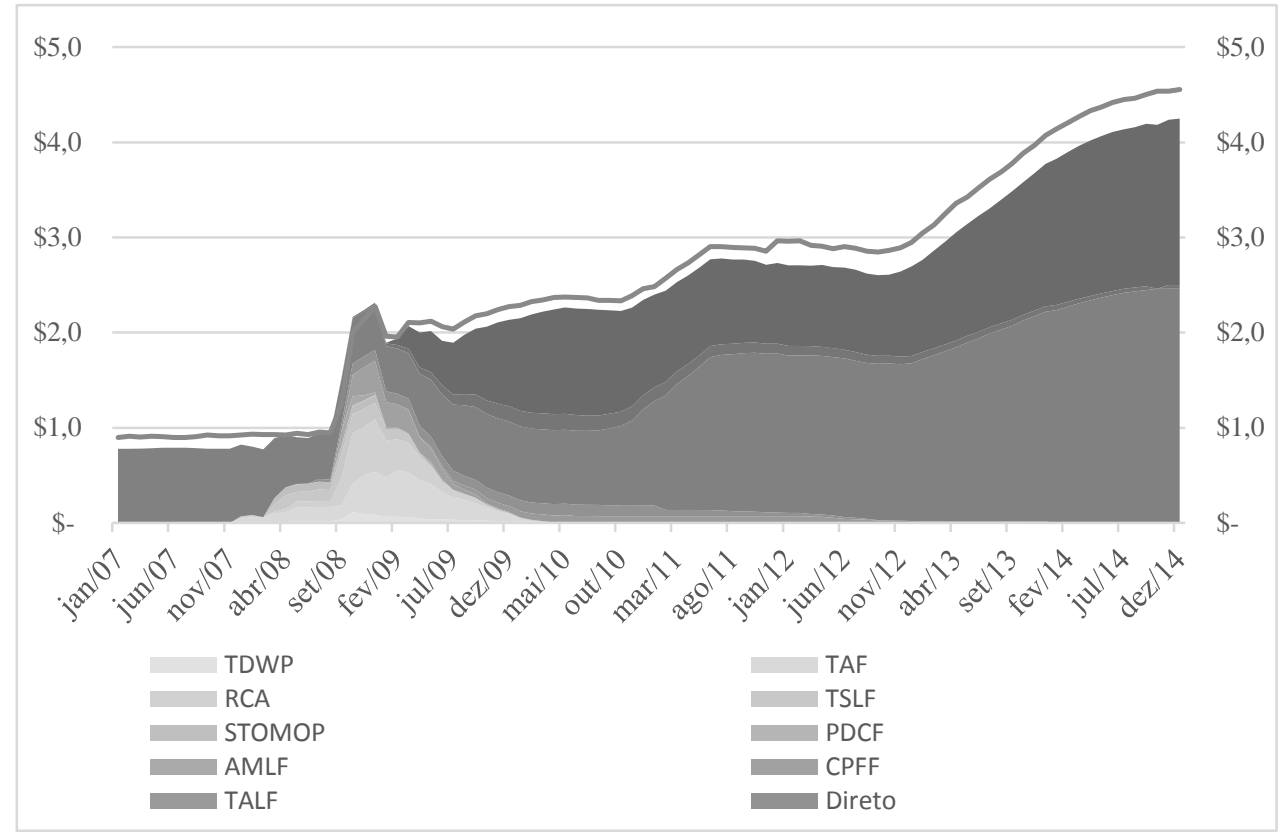

Fonte: Elaboração própria a partir do Board of Governors of the Federal Reserve System, 2014.

\section{Impacto das políticas monetárias não-convencionais ${ }^{25}$}

Nesta seção é analisado um amplo conjunto de estudos empíricos que buscaram medir o impacto e a magnitude das PMNC sobre as condições financeiras e macroeconômicas da economia americana. Tais análises foram subdivididas em

(25) Um resumo da literatura aqui reportada pode ser visto no Anexo 2. 
duas seções. Na seção 3.1, as políticas de crédito e as políticas de quase débito são avaliadas no que se refere aos efeitos sobre o spread de juros, as taxas de juros de longo prazo, o volume de crédito financeiro e a liquidez nos mercados financeiros. Na segunda seção 3.2, por sua vez, avalia-se estudos empíricos acerca dos impactos das políticas de quase débito sobre as variáveis macroeconômicas, com ênfase nas suas implicações sobre a reversão da tendência de recessão e estímulos ao crescimento do produto e do emprego.

\subsection{Evidências empíricas dos impactos sobre as condições financeiras}

Segundo Wu (2008), as tensões financeiras no mercado interbancário, observadas desde o início da crise financeiras de 2007, são resultado de duas questões: i) risco de inadimplência de contraparte entre os empréstimos das instituições financeiras; e ii) aumento de preferência pela liquidez. Como resultado, tem-se uma redução do volume de empréstimos e concomitante aumento nos custos de empréstimos. Deste modo, as medidas de provisão de liquidez e empréstimos promovidos pelo Fed, objetivaram reduzir estas tensões de mercado e foram avaliadas por diversos estudos, focando em particular nos efeitos do TAF, TSLF e RCA, sendo que para as demais ações não foram realizadas análises formais. Segundo Cecioni et al. (2011, p. 20) tais medidas contribuiram para aliviar as tensões no mercado financeiro: "However, the heavy recourse to this group of facilities suggests that they were perceived by depository institutions and by primary dealers as effective in alleviating the significant funding tensions to which they were exposed during the crisis".

Durante a primeira fase da crise financeira, observou-se uma forte elevação entre o spread da taxa overnight dos empréstimos interbancários dos EUA em relação a taxa interbancária de Londres (Libor). Dado que os empréstimos no mercado americano utilizam a Libor como referência, o aumento do spread promoveu uma elevação nos custos dos empréstimos e, deste modo, tornou-se alvo de diversas políticas de crédito, em especial do TAF (Taylor e Williams, 2008). Diversos estudos foram realizados para o período que antecede a quebra do Lehman Brothers e pode-se observar que os resultados não são convergentes, apontando para um impacto incerto desta medida, bem como de sua magnitude, sobre a melhora da liquidez e da taxa de juros do mercado interbancário. Estes estudos utilizaram como medida de eficácia o impacto do TAF sobre o spread da Libor-IOS ${ }^{26}$, embora esta metodologia seja questionada, por alguns estudos. Estes são resumidamente apresentados a seguir.

(26) A relação da Libor spread sobre a taxa de Overnight swap interbancário (OIS) é uma medida frequentemente utilizado nos mercados financeiros para medir a tensão no mercado monetário interbancário (Wu, 2008). 
A crítica à efetividade do TAF foi feita inicialmente por Taylor e Williams (2008), que avaliaram o impacto desta medida sobre a evolução do spread entre a Libor e a OIS e não encontraram efeito significativo, de modo que concluem contra a eficácia da medida. Contudo, McAndrews et al. (2008) questionam os resultados deste trabalho e obtém resultados de que o TAF promoveu uma redução de 50 pontos base (p.b.) no spread da Libor - IOS para três meses. Um resultado similar é obtido por WU (2008), que identifica o TAF como o instrumento mais eficiente do que o PDCF e o TSLF em reduzir as tensões dos mercados interfinanceiros, principalmente em relação aos problemas de liquidez enfrentados pelas instituições financeiras.

Sarkar e Shrader (2010) encontram evidências de que o programa promoveu uma queda no spread da Libor-IOS, além de observarem que a redução dos estímulos não causou impacto negativo sobre esta taxa. De modo complementar, Christensen et al. (2009) avaliam o efeito da TAF sobre a redução do prêmio de liquidez da taxa de juros do interbancário e deste para a redução de 70 p.b. no spread da Libor - IOS para três meses. Segundo os autores, os resultados econométricos sugerem que na ausência desta medida o spread da Libor-IOS teria sido muito superior aos observados. Contudo, estes resultados em favor da TAF são questionados por Thornton (2010, p.23) que argumenta que o aumento da Libor deveu-se a elevação dos riscos dos títulos financeiros e não o prêmio de liquidez: "I then show that the majority of the 3-month LIBOR/T-bill spread before and after the TAF announcement can be accounted for by the spreads between financial and nonfinancial corporate bond rates. Further analysis using daily data indicates that controlling for these risk premiums, TAF appears to have had little or no effect on the 3-month LIBOR/T-bill spread".

Estudos mais recentes, realizados por Shin (2011) e Benmelech (2012), enfatizaram outro aspecto relacionado ao TAF, no qual identificam que este instrumento foi importante particularmente para as instituições depositárias estrangeiras (principalmente bancos europeus) que operavam no mercado americano. Esses, ao longo dos anos que antecederam a crise, ampliam significativamente a sua participação no mercado americano ${ }^{27}$ e foram responsáveis por cerca de $60 \%$ do total de empréstimos concedidos pelo TAF. Tal fato se deve ao descasamento de moeda no balanço destas instituições, principalmente do passivo de curto prazo, e consequentemente a necessidade de dólares, destas instituições, para o cumprimento de suas obrigações.

Um segundo grupo de estudos empíricos buscou avaliar a efetividade do Term Securities Lending Facility (TSFL) na redução do spread entre diversas

(27) Segundo Shin (2011, p. 3) "the US-dollar denominated assets of banks outside the United States are comparable in size to the total assets of the US commercial banking sector, peaking at over $\$ 10$ trillion prior to the crisis. The BIS banking statistics reveal that a substantial portion of external US dollar claims are the claims of European banks against US counterparties". 
garantias oferecidas nas operações compromissadas. Particularmente, esta medida buscou reduzir os custos da utilização de ativos menos líquidos (como dívida de agência e MBS) em relação aos títulos do Tesouro. Esta operação envolveu os dealers que passaram a emprestar uma quantidade de títulos do Tesouro pertencentes ao Fed, aceitando como colateral outros títulos menos líquidos. Segundo Fleming et al. (2010), o TSFL promoveu uma redução significativa do spread nas operações compromissadas. Os autores encontraram evidências de que para cada US\$ 1 bilhão de títulos públicos utilizados no TSFL ocorreu uma redução de 0,40 p.b. nas taxas de juros dos títulos de agência MBS, e, assim, concluem que: "The TSLF does affect the composition of collateral in the market, and overnight repo rates and spreads are highly sensitive to supply changes on TSLF settlement days, but insensitive to expectations of future changes in supply" (Fleming et al., 2010, p. 23).

Ressalta-se que este resultado também é confirmado por Hrung e Seligman (2011). Segundo os autores, o TSFL foi "excepcionalmente" eficiente para atender a necessidade de liquidez no mercado monetário quando comparado a outras medidas implantadas. Ademais foi eficiente para conter o efeito do aumento da demanda por títulos públicos e seu impacto sobre as taxas de juros destes. Tal questão é importante na medida em que esta pressão altista tende a deslocar o preço de mercado dos títulos públicos e, consequentemente, a taxa de juros destes em relação a meta do federal funds rate.

Outro aspecto importante, refere-se ao fato de que a crise financeira foi iniciada no mercado de sub-prime e rapidamente se espalhou para os mercados de crédito e produtos securitizados, impactando significativamente nos mercados monetários e na volatilidade das taxas de juros (OIS). Em decorrência deste cenário e do efeito sobre os mercados financeiros globais, ocorreu uma forte volatilidade no mercado cambial, que pode ser observada nos contratos de swap cambial, como por exemplo, nos contratos de swap dólar/libor de 3 meses, que tiveram um aumento de 40 p.b. em setembro de 2007 e atingiram 340 p.b. no segundo semestre de 2008 (Baba et al., 2008; Baba; Packer, 2009).

Jones (2009), por sua vez, apresenta evidências de que a paridade coberta de juros (Covered Interest Parity - CPI) medida para os países do G10 tem sido violada desde o início da crise. Tais evidencias invalidam a suposição de equilíbrio nos mercados cambiais, sendo que este é um dos principais exemplos da hipótese de mercados internacionais eficientes.

Baba e Packer (2009) avaliam os impactos dos Reciprocal Currency Agreements (RCA), identificando que esta medida promoveu melhorias nos mercados de swap cambial. Os leilões de dólares, promovidos pelo Banco Central Europeu, Banco Central da Inglaterra e Banco Central Suíço, por meio dos contratos 
destes com o Fed, tiveram resultados efetivos na redução da volatilidade e dos desvios de swaps cambiais entre a moeda destes países e o dólar americano.

A segunda fase da crise importou na ampliação das medidas que já vinham sendo adotadas, bem como representou a implantação de um novo conjunto de medidas não convencionais, destacando, como já visto, a AMLF, CPFF, TALF e LSAP. Estas promoveram uma ampliação sem precedentes no balanço do Fed e segundo Blinder (2010) tiveram um caráter mais sistemático e teoricamente embasado, ao mesmo tempo em que a ruptura nos mercados financeiros e a queda da atividade econômica foram bem mais fortes.

Quanto à linha de financiamento do Fed Asset Backed Paper Money Market Fund Liquidity Facility Comercial (AMLF), Duygan-Bump et al. (2010) sustentam que as evidências empíricas corroboram que a intervenção nos mercados secundários de Asset Backed Commercial Paper (ABCP), através dos empréstimos do Fed às instituições depositárias para que estas adquirissem estes títulos, ajudou a estabilizar o volume de resgastes dos fundos mútuos de mercado monetário, bem como promoveu a melhoria da liquidez nos mercados de ABCP. Assim, segundo DuyganBump et al. (2010, p. 4): "Comparing the overnight yield on an ABCP conduit sponsored by a financial institution with the same financial institution's unsecured commercial paper yields, we find that the AMLF reduced ABCP yields by about 80 basis points, on average". Contudo, apesar dos resultados positivos obtidos pelos autores, observou-se nestes mercados um aumento das taxas de empréstimos para os períodos mais longos, além da necessidade das empresas realizarem refinanciamento diário.

Como visto na seção 2, o Fed buscou ampliar a liquidez e o prazo de vencimento nos mercados secundários de ABCP, e lançou de modo similar ao AMLF um novo programa chamado de Commercial Paper Funding Facility (CPFF). Segundo Anderson e Gascon (2009) observa-se que após as primeiras compras dos recém-emitidos commercial paper para 3 meses, na qual o programa absorveu quase a sua totalidade, as empresas continuaram a emitir estes papéis e apenas uma parcela pequena foi comprada por meio do programa. Este resultado também é corroborado por Adrian et al. (2010), que encontram um aumento no prazo das emissões de commercial paper, bem como na redução dos spreads a partir da implantação desta medida.

Ressalta-se que Duca (2011) obtém evidências de que o CPFF promoveu uma reversão da tendência de crescimento do financiamento bancário de curto prazo, gerando uma queda no volume de empréstimos bancários em detrimento do financiamento via commercial paper, que com o programa teve uma redução significativa na taxa de spread e melhoria nas condições de liquidez do mercado, estimulando a ampliação dos empréstimos nesta modalidade. $\mathrm{O}$ autor conclui a favor 
destes programas, com base na comparação com a crise 1929, na qual a ausência de medidas, como as observadas na crise atual, ocasionou o colapso no mercado de títulos monetários.

Finalmente, deve-se ressaltar que alguns trabalhos buscaram analisar o efeito da implantação do Term Asset-Backed Securities Loan Facility - TALF sobre o mercado de securities. Agarwal et al. (2010) encontram evidências de que este programa promoveu a recuperação das emissões de ABS, bem como uma redução dos spreads de 200 a 300 pontos base, para os títulos classificados com rating igual a AAA. Resultados similares são apresentados por Campbell et al. (2011), que identificou a redução nos spreads de ABS e CMBS de 10 a 60 e 50 a 150 pontos base, respectivamente. Contudo, os autores não encontram evidências sobre o efeito direto do programa sobre títulos específicos, alguns dos quais objeto de intervenção do programa, de modo que concluem a favor dos impactos positivos do TALF sobre as condições mais gerais do mercado de ABS.

A compra definitiva de ativos pelo Fed não exibiu a mesma convergência em termos de adequação e efetividade. A utilização de políticas de quase débito gerou um amplo debate e muitas críticas, embora a maioria dos estudos abordados ao longo desta seção sinalize para a existência de impactos positivos destas medidas na redução das taxas de juros longas, melhoria das condições mais gerais dos mercados financeiros e da atividade econômica. Neste ponto, deve-se ressaltar que a efetividade destas políticas, embora não necessariamente a concordância com a implantação destas, é compartilhada por Bernanke (2012b e 2012b), Yellen (2011a, 2011b), Mishkin (2012), Blanchard et al. (2013), Blinder (2010) e Borio et al. (2009) e questionada por Stroebel e Taylor (2009).

Numa abordagem mais ampla, Bernanke (2012a) aponta para uma convergência entre diversos estudos realizados. Tais estudos apontam que o QE I promoveu uma redução entre 40 e 110 p.b. na taxa de juros dos títulos do Tesouro com vencimento para 10 anos, ao passo que o segundo QE II gerou uma redução entre 15 e 45 p.b., nesta mesma taxa. Quando mensurado o volume total das compras de ativos pelo Fed, inclusive o MEP, o impacto sobre a taxa de juros de 10 anos teve uma diminuição entre 80 e 120 pontos base. Ademais, os estudos empíricos têm mostrado queda dos rendimentos dos títulos corporativos e MBS, bem como um efeito positivo sobre o mercado acionário. Consequentemente, segundo Bernanke (2012a, p. 8), tais programas diminuiram os riscos deflacionários: "Overall, however, a balanced reading of the evidence supports the conclusion that central bank securities purchases have provided meaningful support to the economic recovery while mitigating deflationary risks".

Segundo Stroebel e Taylor (2009), a compra de MBS realizada pelo QE I teve um impacto pequeno e incerto sobre as taxas de juros do mercado hipotecário, 
estimado entre 30 e 60 p.b., uma vez que a relação entre as compras de títulos e o spread não foram significativas. Segundo os autores, as mudanças nestas taxas são mais bem explicadas pelas alterações em relação ao risco de default e não pela compra destes títulos. Como resultado, concluem que este programa não corresponde a uma política monetária eficiente. Este resultado não é corroborado por Hancock e Passmore (2011) que encontram evidência de uma redução no spread de 85 p.b. logo após o anúncio da medida e 50 p.b. após a implantação do programa. Destaca-se que, segundo os autores, esta medida permitiu o reestabelecimento do mercado de MBS, que se manteve com taxas mais baixas mesmo após a conclusão do programa.

Esta redução nas taxas de juros de longo prazo dos ativos e no funcionamento dos mercados hipotecários é confirmada por Fuster e Willen (2010), que registraram uma redução significativa na taxa de juros paga pelos mutuários. Contudo, mostram ainda que as variações na taxa de juros, tanto no anúncio do programa (entre 10 e 41 p.b.), quanto nas operações de compra (entre 16 e 60 p.b.), foram significativas. Tal resultado é explicado pela diferença entre a qualidade de risco dos mutuários. Ademais, observou-se uma mudança substancial no perfil dos mutuários ao longo do programa, ampliando a participação de mutuários com melhores pontuações de crédito.

No que se refere aos efeitos das compras de títulos de longo prazo do Tesouro, os estudos empíricos apoiam a eficácia na redução da taxa de juros de longo prazo, embora a magnitude de seus efeitos seja a principal divergência entre os trabalhos analisados. Gagnon et al. (2011) analisam o impacto do QE I sobre a taxa de juros de longo prazo (10 anos) de títulos do governo, dívida de agência e MBS. Os autores, utilizando-se de duas metodologias diferentes, encontram resultados similares, no qual o programa foi capaz de reduzir o prêmio de risco destes títulos que variou entre 30 e 300 p.b. Ademais, concluem que os impactos foram mais significativos para os títulos de dívida de agência e MBS, além de terem demonstrado que a PMNC é eficiente quando a taxa de juros de curto prazo encontrase próxima ao limite inferior.

Este resultado também é corroborado por Yellen (2011b) que identifica a forte relação entre os anúncios e compras de ativos pelo Fed e as variações nas taxas de juros de longo prazo. Os impactos do QE1 sobre os títulos do Tesouro com vencimento para 10 anos tiveram uma redução de 107 p.b. Ademais, a autora argumenta que este resultado é confirmado por diversos estudos empíricos: "Both theory and empirical evidence suggest that asset prices and yields are affected not only by current securities purchases but also, importantly, by market expectations concerning future FOMC securities holdings" (Yellen, 2011b, p. 6). Ressalta-se que D'amico e King (2010) estimam que o impacto da compra de US\$ 400 bilhões em títulos do Tesouro de longo prazo, promoveu uma redução de 67 p.b. Neste ponto deve-se destacar ainda que Krishnamurthy e Vissing-Jorgensen (2011) identificam 
que o QE1 e QE2 promoveram, respectivamente, uma queda de 100 e 30 p.b. nas taxas de juros de longo prazo dos títulos públicos. Este resultado é confirmado por Swanson (2011) que estima o impacto do QE2 na queda de 15 p.b. nos títulos de 10 anos do Tesouro.

Outro conjunto de estudos, segundo (Cecioni et al., 2011, p. 24), utilizou a metodologia de séries temporais e obteve resultados que confirmam a efetividade da política de compra de títulos, embora a magnitude deste efeito seja bem menor do que os estudos apresentados. Especificamente, estes estudos, desenvolvidos por Hamilton e Wu (2011), Vayanos e Vila (2009) e Gagnon et al. (2010) e Greenwood e Vayanos (2010), buscaram avaliar os impactos das compras esterilizadas no montante de US\$ 400 bilhões de títulos do Tesouro de longo prazo que foram trocados por títulos de curto prazo. Os resultados obtidos variam entre 14 p.b. e 40 p.b. Ressalta-se que Fuhrer e Olivei (2011) partem destas estimativas para analisarem os impactos do QE2 sobre as variáveis macroeconômicos, utilizando para tanto um intervalo de 20 a 30 p.b. sobre os títulos do Tesouro com vencimentos de 10 anos. Williams (2010) normalizou estes valores, a partir de diversos estudos ${ }^{28}$, para medir o efeito da compra de títulos públicos no montante de US\$ 600 bilhões, sendo que as estimativas variam de 15 p.b. até 100 p.b.

Contudo, observam-se vários questionamentos, além dos efeitos que estas políticas de compra de títulos tiveram sobre a taxa de juros dos títulos do Tesouro de longo prazo. Segundo Curdia e Woodford (2010), a ampliação na base monetária não resultou em uma expansão na oferta de moeda na economia e aumento do volume de crédito, uma vez que a maior parte desta expansão se transformou em reservas voluntárias dos bancos comerciais depositadas no Fed. Um segundo ponto refere-se à impossibilidade destas políticas afetarem as taxas de juros de curto prazo que estavam estacionadas próximo a zero e, deste modo, limitou significativamente o seu efeito sobre a atividade econômica.

\subsection{Evidências empíricas dos impactos sobre as condições macroeconômicas}

As políticas monetárias não-convencionais (PMNC) almejaram indiretamente, como no caso das políticas de crédito, ou diretamente, como no caso das políticas de quase débito, afetar as variáveis macroeconômicas nos EUA. Em boa medida, as análises empíricas sobre os impactos macroeconômicos buscam responder quais foram os efeitos e a magnitude destas políticas sobre o produto (demanda agregada) e a taxa de desemprego, na redução das taxas de juros de longo prazo, dos spreads de crédito, do risco de iliquidez e da volatilidade cambial. Segundo Cecioni et al. (2011) o fornecimento de liquidez reduz o spread dos

(28) Krishnamurthy-Vissing et al. (2011); D`Amico e King (2010); Hamilton e Wu (2011); Hancock e Passmore (2011) e Swanson (2011). 
empréstimos nos mercados interbancários, de crédito e títulos e deste modo estimulam a decisões de consumo e investimento. Por sua vez, a melhoria nos preços dos ativos impacta sobre a demanda via efeito riqueza e "q de Tobin" e as variações cambiais afetam o saldo líquido das exportações.

Nesta perspectiva, diversos estudos focaram nos efeitos destas políticas sobre o produto e o emprego. Baumeister e Benati (2010) identificam que um choque no spread de títulos de longo prazo tem forte impacto sobre o nível de atividade e sobre os preços dos ativos da economia. Segundo os autores, na ausência das políticas de compra de títulos (QE), a manutenção dos spreads elevados provocaria uma redução do PIB dos EUA em $10 \%$ no primeiro semestre de 2009, ao passo que a inflação teria permanecido negativa ao longo deste ano. De modo similar, porém utilizando um modelo DSGE, Del Negro et al. (2010), avaliam o impulso de um choque de iliquidez, na qual a utilização de política não convencional impede a ocorrência de um colapso na atividade econômica, bem como da persistência da deflação. Os autores concluem que: "that non-standard policy can have large effects. This is particularly true at zero interest rates. We showed a numerical example that in the absence of non-standard, the model economy generates the Great Depression" (Del Negro et al., 2010, p. 30).

Utilizando técnica de modelagem estocástica, Chung et al. (2011) apresentam simulações, nas quais a evolução do programa de compra de títulos pelo Fed (QE1 e QE2) ao longo do período de 2009 a 2011 é equivalente aos estímulos gerados por uma redução de 300 p.b. nas taxas de juros de curto prazo em períodos normais. As simulações, segundo os autores, apontam para um impulso gerado pelo quantitative easing para 2012 de aumento de 3\% na atividade econômica, redução da taxa de desemprego em 1,5\%, além de impedir que a economia americana entrasse em deflação.

Outro estudo, desenvolvido por Fuherer e Olivei (2011), combina os resultados de estudos empíricos - séries temporais e modelos estruturais do Fed -, alcançando resultados de que a compra de títulos durante o QE2 (US\$ 600 bilhões) tende a promover um crescimento do PIB entre 75 e 80 p.b. e redução do desemprego entre 0,3 e 0,4 pp, o que equivale a criação de 700.000 empregos, com um efeito defasado de 1 a 2 anos.

Meinusch et al. (2014) avaliam o impacto do QE1, QE2 e QE3, e encontram evidências de efeito sobre o crescimento da produção industrial de $1 \%$ após um ano e $0,4 \%$ no emprego. De modo convergente com a metodologia e os resultados anteriores, Yellen (2011a) argumenta que os impactos e a magnitude do quantitative easing podem ser medidos pela utilização dos modelos macro econométricos do Federal Reserve. Segundo a autora a recessão se iniciou em dezembro de 2007, porém as condições macroeconômicas tiveram uma piora significativa nos anos 
subsequentes. A taxa de desemprego nos EUA, que até 2007 estava abaixo das estimativas de NAIRU em torno de 5\%, atingiu cerca de $10 \%$ em outubro de 2009 e desde então permaneceu acima dos 9\%. Neste contexto, Yellen (2011a, p. 7-8) sustenta que o programa de compras de títulos de longo prazo promoveu até o ano de 2012 a criação de 3 milhões de empregos.

Finalmente, deve-se ressaltar que Bernanke (2012b, p. 8) afirma que, embora não se possa assegurar categoricamente que as políticas de quase débito foram efetivas na contenção da recessão e da deflação, além da retomada do crescimento econômico, "[a] balanced reading of the evidence supports the conclusion that central bank securities purchases have provided meaningful support to the economic recovery while mitigating deflationary risks". Ademais, o autor observa que as políticas de quase-débito, não se limitaram à redução das taxas de juros de títulos do Tesouro, impactando substancialmente sobre os preços de outros ativos, como as MBS, as taxas de varejo das hipotecas e dos títulos corporativos, além de ter afetado positivamente os preços e as condições nos mercados de ações. E conclui que: "This effect is potentially important because stock values affect both consumption and investment decisions" (Bernanke, 2012b, p. 7).

\section{Considerações finais}

A crise financeira de 2007 foi enfrentada inicialmente pelo Fed por meio de instrumentos convencionais, reduzindo as taxas de juros de curto prazo através das operações de mercado aberto e provendo liquidez ao sistema bancário, enquanto emprestador de última instância. Nesta primeira fase, as operações de mercado aberto reduziram o federal funds rate de 5,25\% a.a. para $2 \%$ a.a., enquanto os instrumentos de redesconto ampliado atuaram sobre a provisão de liquidez ofertando moeda e emprestando títulos do Tesouro para os dealers primários, além das instituições depositárias. Contudo, em setembro de 2008 "tudo mudou" e um "novo mundo surgiu". A quebra do Lehman Brothers, os problemas na AIG e a paralização do mercado interbancário, "lançaram a economia para um precipício" e por pouco “o fim não chegou”. Estas expressões não convencionais, utilizadas por Mishkin e Bernanke, ajudam a entender a gravidade e a dimensão sistêmica da segunda fase da crise financeira americana.

Esta segunda fase representou uma forte ruptura operacional da condução da PM do NCM em relação aos instrumentos, particularmente para uma situação na qual a taxa de juros de curto prazo aproxima-se de zero. A diferença substancial das novas políticas de crédito implementadas foi o seu montante, bem como o seu direcionamento para mercados específicos (mercados monetários, títulos de agências e títulos corporativos) e instituições não depositárias (bancos de investimento, agências e fundos de investimento). No que se refere às operações definitivas de mercado aberto, o Fed promoveu uma compra sem precedentes de dívida de 
agências, títulos de agência (MBS), títulos do Tesouro de longo prazo, além da troca de títulos do Tesouro de longo prazo por títulos de curto prazo.

Na medida em que os problemas de liquidez e prêmio de risco foram sendo resolvidos, as políticas de crédito foram sendo removidas ao longo do ano de 2009. Contudo, isto não representou uma redução dos estímulos, pois a queda destas foi mais do que compensada pelas políticas de quase débito, que almejavam reverter a tendência de estagnação e recessão da atividade econômica. Como decorrência destas medidas, observa-se que o balancete do Fed saltou de US\$ 950 bilhões em agosto de 2008 para US\$ 2,3 trilhões em dezembro de 2008 e para US\$ 4 trilhões em dezembro de 2013.

Neste contexto de larga utilização de PMNC, instaurou-se debate quanto à efetividade e adequação destas medidas (ver anexo 2). Além das questões teóricas e ideológicas subjacentes destaca-se um esforço de mensuração e de apresentação de evidências empíricas. De forma geral, pode-se dizer que as políticas de crédito apresentaram efeitos positivos sobre as condições de liquidez e as diferentes medidas de spread (notadamente o OIS). Contudo, esta não é a observação em relação às políticas de quase débito, cujos impactos e magnitude, embora efetivos (inclusive no que se refere a variáveis reais, como produto e emprego), são alvo de maiores questionamentos e, portanto, merecem novas avaliações.

Note que a conclusão pela efetividade das PMNC (sobre as variáveis financeiras e macroeconômicas) se baseia em resultados empíricos obtidos em diversos estudos com base nas mais variadas metodologias. No entanto, pode-se supor que estas políticas foram ainda mais eficazes do que os resultados à primeira vista sugerem. Isto por que, a prova contra factual, que demonstraria os impactos da crise na ausência destas medidas, não existe. As PMNC, além contribuir para o reestabelecimento das condições normais de mercado, tiveram que reverter a tendência desagregadora de uma ruptura financeira.

Entretanto, mesmo aceitando-se a efetividade das PMNC, não se pode ignorar seu elevado custo financeiro. É inquestionável que a sua efetividade - face ao tamanho, a segmentação do mercado americano, e as características de um sistema de meios de pagamentos fracionário - dependeu de um volume extraordinário de recursos monetários e financeiros (e de uma gama de programas). Em termos de estoque, as medidas adotadas representaram uma expansão da ordem de US\$ 3,2 trilhões no balanço do Fed (janeiro de 2007 a dezembro de 2013); ao passo que o fluxo de empréstimos e de compras equivale a um montante que extrapola US\$ 30 trilhões ao longo do período de análise.

Finalmente, contesta-se a proposição do Novo Consenso Macroeconômico segundo a qual - quando as taxas curtas se encontram próximo a zero - a orientação para frente da PM seria o único instrumento capaz de afetar a taxa de juros de longo 
prazo e, portanto, a demanda agregada. Esta proposição é contradita pelas evidências empíricas quanto a efetividade de outros instrumentos de PMNC. Assim, pode-se concluir que a moeda não é neutra: ela afeta as decisões dos agentes econômicos e, consequentemente, o produto e o emprego de uma economia. Se as políticas de quase débito são capazes de afetar uma economia em crise - com elevada preferência pela liquidez - elas também podem ser eficazes em períodos de maior normalidade econômica.

Ademais, a ampla utilização de PMNC, mesmo antes da taxa (básica) de juros convergir para zero, demonstra que a armadilha da liquidez pode ocorrer para níveis de taxa de juros superiores a zero (zero lower bound); e que, a política monetária convencional (manipulação de taxa de juros) e a orientação para frente da PM (via gestão de expectativas quanto ao comportamento futuro da taxa de juros) não foram eficazes para lidar com a elevação da preferência pela liquidez dos agentes. Estas questões teóricas e empíricas são relevantes e, portanto, merecem ser aprofundadas em outros trabalhos.

\section{Referências bibliográficas}

ADRIAN, T.; KIMBROUGH, K.; MARCHIONI, D. The Federal Reserve's Commercial Paper Funding Facility. FRBNY Economic Policy Review, v. 17, n.1, p. 25-39, 2011.

AGARWAL, S.; BARRETT, J.; CUN, C.; DE NARDI, M. The asset-backed securities markets, the crisis, and TALF. Economic Perspectives, Federal Reserve Bank of Chicago, 4th quarter, p. 101-115, 2010.

ANDERSON, R.; GASCON, C. The commercial paper market, the Fed, and the 2007- 2009 financial crisis. Federal Reserve Bank of St. Louis Review, v. 91, n. 6, p. 589-612, 2009.

ANDO, A.; MODIGLIANI, F. The "life-cycle" hypothesis of saving: aggregate implications and tests. American Economic Review, v. 53, n. 1, p. 55-84, 1963.

BABA, N.; PACKER, F.; NAGANO, T. The spillover of money market turbulence to FX swap and cross-currency swap markets. BIS Quarterly Review, p. 73-86, mar., 2008.

BABA, N.; PACKER, F. From turmoil to crisis: dislocations in the FX swap market before and after the failure of Lehman Brothers. Switzerland: Bank for International Settlements, 2009. (BIS Working Papers, n. 285).

BAUMEISTER, C.; BENATI, L. Unconventional monetary policy and the great recession. Frankfurt: European Central Bank, Oct, 2010. (ECB Working Paper Series, n. 1258). 
BENMELECH, E. An empirical analysis of the Fed's term auction facility. Cato Papers on Public Policy, 2012.

BERNANKE, B. The great moderation. Remarks before the Eastern Economic Association. Washington, DC, Feb. 20, 2004.

BERNANKE B. Some reflections on the crisis and the policy response. The Century Foundation Conference on "Rethinking Finance", New York, 13 Apr. 2012a.

BERNANKE, B. Monetary policy since the onset of the crisis. The Federal Reserve Bank de Kansas City Economic Symposium, Jackson Hole, Wyoming, 31 Aug. 2012b.

BERNANKE, B.; BLINDER, A. Credit, money and aggregate demand. American Economic Review, v. 78, n. 2, p. 435-439, 1989.

BERNANKE, B.; GERTLER, M. Inside the black box: the credit channel of monetary policy transmission. Journal of Economic Perspectives, v. 9, n. 4, p. 27 $48,1995$.

BERNANKE, B.; GERTLER, M. Monetary policy and asset volatility. Federal Reserve Bank of Kansas City Economic Review, v. 84, n. 4, p. 17-52, 1999.

BERNANKE, B.; GERTLER, M. Should Central Banks respond to movements in asset prices? American Economic Review, v. 91, n. 2, p. 253-257, 2001.

BLANCHARD, O. Is there a core of usable macroeconomics? The American Economic Review, v. 87, n. 2, p. 244-246, May 1997.

BLANCHARD, O.; DELL'ARICCIA, M.; MAURO, P. Rethinking macroeconomic policy. Journal of Money, Credit and Banking, v. 42, n. 6, p. 199-215, 2010.

BLANCHARD, O.; DELL'ARICCIA, M. Rethinking macro policy II: getting granular. Washington, DC: International Monetary Fund, Apr. 2013. p. 199-215. (IMF Staff Discussion Note).

BLINDER, A. Is there a core of practical macroeconomics that we would all believe? The American Economic Review, v. 87, n. 2, p. 240-243, May 1997.

BLINDER, A. Quantitative easing: entrance and exit strategies. Brussels: Centre for European Policy Studies, Mar. 2010. (CEPS Working Paper, n. 204).

BOARD OF GOVERNORS OF THE FEDERAL RESERVE SYSTEM (US). Economic Research \& Data. Disponível em: https://www.federalreserve.gov/econresdata/\%20default.htm. Acesso entre: out. de 2013 a mar. 2015. 
BORIO, C.; DISYATAT, P. Unconventional monetary policies: monetary and economic. Switzerland: Bank for International Settlements, Nov. 2009. (BIS Working Papers, n. 292).

BULliO, O.; FERRARA, N. F.; CUNHA, P.; CARVALHO, C. E. A atuação do Fed antes e depois do estouro da bolha imobiliária: discricionariedade e mandato de bancos centrais em contexto de desregulamentação financeira. Economia $e$ Sociedade, v. 20, n. 2 (42), p. 329-364, Ago. 2011.

CAMPBELL, S.; COVITZ, D.; NELSON, W.; PENCE, K. Securitization markets and Central Banking: an evaluation of the term asset-backed securities loan facility. St. Louis: Federal Reserve Board, Jan. 2011. (Finance and Economics Discussion Series, n. 16).

CARVALHO, F.C.; SOUZA, F..E.; SICSÚ, J.; PAULA, L.F.; STUDART, R. Economia monetária e financeira. 3. ed. Rio de Janeiro: Campus/Elsevier, 2015.

CECIONI, M.; FERRERO G.; SECCHI, A. Unconventional monetary policy in theory and in practice. [s.l.]: Economic Outlook and Monetary Policy Research Department, Sept. 2011. (Bank of Italy Occasional Paper, n. 102)

CHUNG, H.; LAFORTE, J.; REIFSCHNEIDER, D.; WILLIAMS, J. Have we underestimated the probability of hitting the zero lower bound? San Francisco: Federal Reserve Bank of San Francisco, 2011. (Working Paper, n. 2011-01).

CURDIA, V.; WOODFORD, M. Conventional and unconventional monetary policy. Federal Reserve Bank of St. Louis Review, p. 229-264, May 2010.

CHRISTENSEN, J.; LOPEZ, J.; RUDEBUSCH, G. Do Central Bank liquidity facilities affect interbank lending rates? San Francisco: Federal Reserve Bank of San Francisco, Jun. 2009. (Working Paper, n. 13).

D'AMICO, S.; KING, T. Flow and stock effects of large-scale treasury purchases. [s.1.]: Board of Governors of the Federal Reserve System, 2010. (Finance and Economics Discussion Series).

DAVIDSON, P. Can, or should, a Central Bank inflation target? Journal of Post Keynesian Economics, v. 28, n. 4, p. 689-703, Summer 2006.

DEL NEGRO, M.; EGGERTSSON, G.; FERRERO A.; KIYOTAKI, N. The great escape: a quantitative evaluation of Fed non-standard policies. New York: Federal Reserve Bank, 2010. (Manuscript).

DUCA, J. Did the commercial paper funding facility prevent a great depression style money market meltdown? Dallas: Federal Reserve Bank, Research Department, 2011. (Working Paper, n. 1101). 
DUYGAN-BUMP, B.; PARKINSON, P.; ROSENGREN, E.; SUAREZ, G.; WILLEN, P. How effective were the Federal Reserve emergency liquidity facilities? Evidence from the asset-backed commercial paper money market mutual fund liquidity facility. Boston: Federal Reserve Bank. Apr. 2010. (Working Paper, n. QAU10-3).

EGGERTSSON, G.; WOODFORD, M. The zero bound on interest rates and optimal monetary policy. Brookings Papers on Economic Activity, v. 34, p. 139-211, 2003.

FLEMING, M.; HRUNG, W.; KEANE, F. Repo market effects of the term securities lending facility. American Economic Review, v. 100, n. 2, p. 591-596, 2010.

FUHRER, J.; OLIVEI, G. The estimated macroeconomic effects of the Federal Reserve's large-scale treasury purchase program. Boston: Federal Reserve Bank, 2011. (Public Policy Briefs, n. 11-2).

FUSTER, A.; WILLEN, P. \$1.25 trillion is still real money: some facts about the effects of the Federal Reserve mortgage market investments. Boston: Federal Reserve Bank, 2010. (Public Policy Discussion Paper, n. 10-4).

GAGNON, J.; RASKIN, M.; REMACHE, J.; SACKS, B. The financial market effects of the Federal Reserve's large-scale asset purchases. International Journal of Central Banking, v. 7, n. 1, p. 3-43, 2011.

GOODFRIEND, M. The monetary policy debate since october 1979: lessons for theory and practice. Federal Reserve Bank of St. Louis Review, p. 243-262, Mar./Apr. 2005.

GOODFRIEND, M. How the world achieved consensus on monetary policy. Journal of Economic Perspectives, v. 21, n. 4, p. 47-68, 2007.

GREENWOOD, R.; VAYANOS, D. Price pressure in the government bond market. American Economic Review, v. 100, n. 2, p. 585-590, 2010.

HAMILTON, J.; WU, C. The effectiveness of alternative monetary policy tools in a zero lower bound environment. Cambridge, MA: National Bureau of Economic Research, 2011. (NBER Working Paper, n. 16956).

HANCOCK, D.; PASSMORE, W. Did the Federal Reserve's MBS purchase program lower mortgage rates? St. Louis: Federal Reserve Board, 2011. (Finance and Economics Discussion Series).

HRUNG, W.; SELIGMAN, J. Responses to the financial crisis, treasury debt, and the impact on short-term money markets. New York: Federal Reserve Bank, Jan. 2011. (Staff Report, n. 481). 
IMF. World Economic Outlook database: Data and statistic. Washington: International Monetary Fund. Disponivel em: http://www.imf.org/external/data.htm. Acesso: entre março de 2015.

JONES, S. Deviations from covered interest parity during the credit crisis. New York: New York University, Leonard N. Stern School of Business, 2009.

KRISHNAMURTHY, A.; VISSING-JORGENSEN, A. The effects of quantitative easing on interest rates: channels and implications for policy. Cambridge, MA: National Bureau of Economic Research, Oct. 2011. (NBER Working Paper, n. 17555).

MCANDREWS, J.; SARKAR, A.; WANG, Z. The effect of the term auction facility on the London Inter-Bank offered rate. New York: Federal Reserve Bank, Jul. 2008. (Staff Report, n. 33).

MACCALLUM, B. Monetary policy analysis in models without money. FRB Richmond Economic Review, v. 88, n. 1, p. 67-96, 2002.

MEINUSCH, A.; TILLMANN, P. The macroeconomic impact of unconventional monetary policy shocks. Marburg, Germany: Universität Marburg, 2014. (Joint Discussion Paper Series in Economics, n. 26).

MEYER. L. Does money matter? St. Louis: Federal Reserve Bank, Sept./Oct., 2001. p. 1-16.

MISHKIN, F. Central Banking after the crisis. Prepared for the 16th Annual Conference of the Central Bank of Chile. Santiago, Chile, Nov. 15-16, 2012.

MODIGLIANI, F.; SUTCH, R. Innovations in interest-rate policy. American Economic Review, v. 56, n. 1, p. 178-197, 1966.

PAULA, L. F.; SARAIVA, P. Novo consenso macroeconômico e regime de metas de inflação: algumas implicações para o Brasil. Revista Paranaense de Desenvolvimento, v. 36, p. 19-32, 2015.

SARKAR, A.; SHRADER, J. Financial amplification mechanisms and the Federal Reserve's supply of liquidity during the crisis. New York: Federal Reserve Bank, 2010. (Staff Reports, n. 431).

SHIN, H. Global banking glut and loan risk premium. Mundell-Fleming Lecture Conference Draft. Paper presented at the 12th Jacques Polak Annual Research Conference. Washington, DC: International Monetary Fund, 2011.

STROEBEL, J.; TAYLOR, J. Estimated impact of the Fed's Mortgage-Backed Securities Purchase Program. Cambridge, MA: National Bureau of Economic Research, Dec. 2009. (NBER Working Paper Series, n. 15626). 
SWANSON, E. Let's twist again: a high-frequency event-study analysis of operation twist and its implications for QE2. San Francisco: Federal Reserve Bank, 2011. (Working Paper).

TAYLOR, J.; WILLIAMS, J. A black Swan in the money market. Cambridge, MA: National Bureau of Economic Research, Apr. 2008. (NBER Working Paper Series n. 13943).

TAYLOR, J. Core of practical macroeconomics. The American Economic Review, v. 87, n. 2, p. 233-235, May 1997.

TAYLOR, J. Does the crisis experience call for a new paradigm in monetary policy? Warsaw, Poland: CASE - Center for Social and Economic Research, 2010a. (CASE Network Studies and Analyses, n. 402).

TAYLOR, J. Remarks at a panel on the monetary policy implications of the global crisis. Conference Hosted by the Bank of Japan, 16 and 17 Sept. 2010. International Journal of Central Banking, 2010b.

THORNTON, D. The effectiveness of unconventional monetary policy: the term auction facility. St. Louis: Federal Reserve Bank, 2010. (Working Paper Series).

TOBIN, J. A general equilibrium approach to monetary theory. Journal of Money Credit, and Banking, v. 1. n. 1, p. 15-29, Feb. 1969.

VAYANOS, D.; VILA, J. A preferred-habitat model of the term structure of interest rates. Cambridge, MA: National Bureau of Economic Research, 2009. (NBER Working Paper, n. 15487).

WILLAMS, J. Unconventional monetary policy: lessons from the past three years. Presentation to the Swiss National Bank Research Conference Zurich, Sept. 23, 2010.

WOODFORD, M. Convergence in macroeconomics: elements of the new synthesis. American Economic Journal: Macroeconomics, v. 2, n. 1, p. 267-279, 2009.

WU, T. On the effectiveness of the Federal Reserve's new liquidity facilities. Dallas: Federal Reserve Bank. Research Department, May 2008. (Working Paper, n. 0808).

YELLEN, J. Unconventional monetary policy and Central Bank Communications. Speech at The University of Chicago Booth School of Business US Monetary Policy Forum. New York, Feb. 2011a.

YELLEN, J. The Federal Reserve's asset Purchase Program. Speech at the Brimmer Policy Forum, Allied Social Science Associations Annual Meeting, Denver, Colorado, Jan. 8, 2011 b. 


\section{Anexo 1}

Características gerais das PMNC adotadas pelo Fed - agosto de 2007 a dezembro de 2013

\begin{tabular}{|c|c|c|c|c|c|c|c|c|}
\hline & \multicolumn{2}{|c|}{$\begin{array}{l}\text { Período de } \\
\text { vigência }\end{array}$} & \multirow[t]{2}{*}{ Direcionamento } & \multirow[t]{2}{*}{ Demanda } & \multirow[t]{2}{*}{ Colateral } & \multirow{2}{*}{$\begin{array}{l}\text { Prazo de } \\
\text { empréstimo }\end{array}$} & \multirow{2}{*}{$\begin{array}{l}\text { Valores }^{1} \\
\text { (média) e } \\
\text { (máx.) }\end{array}$} & \multirow[t]{2}{*}{ Objetivo } \\
\hline & Inicio & Fim & & & & & & \\
\hline TDWP & Ago/07 & Mar/10 & $\begin{array}{l}\text { Instituições } \\
\text { depositárias }\end{array}$ & Moeda & Idêntico ao redesconto & Até 90 dias & $\begin{array}{c}\text { US\$ } 29 \\
\text { US\$ } 111\end{array}$ & $\begin{array}{l}\text { Provimento de liquidez as } \\
\text { instituições depositárias }\end{array}$ \\
\hline TAF & Dez/07 & Mar/10 & $\begin{array}{l}\text { Instituições } \\
\text { depositárias }\end{array}$ & Moeda & Idêntico ao redesconto & $\begin{array}{l}\text { De } 28 \text { a } 84 \\
\quad \text { dias }\end{array}$ & $\begin{array}{c}\text { US\$ } 78 \\
\text { US\$ } 493\end{array}$ & $\begin{array}{l}\text { Provimento de liquidez as } \\
\text { instituições depositárias }\end{array}$ \\
\hline TSLF & Mar/08 & Fev/10 & Dealers Primários & $\begin{array}{c}\text { Títulos do } \\
\text { Tesouro }\end{array}$ & $\begin{array}{l}\text { Títulos do Tesouro, de } \\
\text { agências, de agências } \\
\text { MBS e título de dívida } \\
\text { com grau de } \\
\text { investimento }\end{array}$ & Até 28 dias & $\begin{array}{c}\text { US\$ } 26 \\
\text { US\$ } 245\end{array}$ & $\begin{array}{l}\text { Provimento de títulos aos } \\
\text { dealers primários }\end{array}$ \\
\hline PDCF & Mar/08 & Jan/10 & Dealers Primários & Moeda & Similar ao redesconto & Overnight & $\begin{array}{c}\text { US\$ } 1 \\
\text { US\$ } 10\end{array}$ & $\begin{array}{l}\text { Provimento de liquidez } \\
\text { aos dealers primários }\end{array}$ \\
\hline AMLF & Set/08 & Fev/10 & $\begin{array}{c}\text { Instituições } \\
\text { Depositárias e } \\
\text { holdings bancárias }\end{array}$ & Moeda & $\begin{array}{c}\mathrm{ABCP}(3) \text { de primeiro } \\
\text { nível }\end{array}$ & $\begin{array}{c}\text { Maturidade } \\
\text { das ABCP } \\
\text { (máxima } 270 \\
\text { dias) } \\
\end{array}$ & $\begin{array}{c}\text { US\$ } 6 \\
\text { US\$ } 151\end{array}$ & $\begin{array}{l}\text { Restaurar a liquidez dos } \\
\text { mercados de ABCP }\end{array}$ \\
\hline $\mathrm{CPFF}$ & Set/08 & Fev/10 & $\begin{array}{l}\text { Emissores elegíveis } \\
\text { de Curto prazo }\end{array}$ & Moeda & $\begin{array}{l}\text { ABCP de primeiro nível } \\
\text { e novas emissões de } \\
\text { ABCP com prazo } \\
\text { máximo de } 3 \text { meses }\end{array}$ & Até 90 dias & $\begin{array}{c}\text { US\$ } 34 \\
\text { US\$ } 331\end{array}$ & $\begin{array}{c}\text { Provimento de liquidez no } \\
\text { mercado de papéis } \\
\text { comerciais }\end{array}$ \\
\hline TALF & Set/08 & Mar/09 & $\begin{array}{l}\text { Todos agentes dos } \\
\text { EUA que possuíam } \\
\text { garantias elegíveis }\end{array}$ & Moeda & $\begin{array}{c}\text { ABS, CMBS com grau } \\
\text { AAA }\end{array}$ & $\begin{array}{c}\text { De } 3 \text { a } 5 \\
\text { anos }\end{array}$ & $\begin{array}{l}\text { US\$ } 47 \\
\text { US\$ } 71\end{array}$ & $\begin{array}{c}\text { Apoio a pequenas } \\
\text { empresas e consumidores }\end{array}$ \\
\hline
\end{tabular}

Continua... 


\begin{tabular}{|c|c|c|c|c|c|c|c|c|}
\hline \multicolumn{9}{|l|}{ Continuação } \\
\hline & \multicolumn{2}{|c|}{$\begin{array}{l}\text { Período de } \\
\text { vigência }\end{array}$} & \multirow[t]{2}{*}{ Direcionamento } & \multirow[t]{2}{*}{ Demanda } & \multirow[t]{2}{*}{ Colateral } & \multirow{2}{*}{$\begin{array}{l}\text { Prazo de } \\
\text { empréstimo }\end{array}$} & \multirow{2}{*}{$\begin{array}{l}\text { Valores }^{1} \\
\text { (média) e } \\
\text { (máx.) }\end{array}$} & \multirow[t]{2}{*}{ Objetivo } \\
\hline & Inicio & Fim & & & & & & \\
\hline RCA & Dez/07 & Set/10 & $\begin{array}{l}\text { Bancos Centrais } \\
\text { estrangeiros }\end{array}$ & Dólares & $\begin{array}{c}\text { Contratos de Swap entre } \\
\text { o Fed e os Bancos } \\
\text { Centrais }\end{array}$ & Até 3 meses & $\begin{array}{l}\text { US\$ } 55 \\
\text { US\$ } 553\end{array}$ & $\begin{array}{l}\text { Provimento liquidez em } \\
\text { dólares aos bancos } \\
\text { centrais estrangeiros }\end{array}$ \\
\hline STOMOP & Mar/08 & Dez/08 & Dealers primários & Moeda & Idêntico ao redesconto & 28 dias & $\begin{array}{l}\text { US\$ } 11 \\
\text { US\$ } 80\end{array}$ & $\begin{array}{l}\text { Provimento de liquidez } \\
\text { aos dealers primários }\end{array}$ \\
\hline ADIF & $\mathrm{Jul} / 08$ & --- & $\begin{array}{l}\text { Instituições } \\
\text { financeiras } \\
\text { específicas }\end{array}$ & Moeda & $\begin{array}{l}\text { Um amplo conjunto de } \\
\text { ativos da carteira das } \\
\text { instituições financeiras } \\
\text { envolvidas }\end{array}$ & $\begin{array}{l}\text { De } 2 \text { a } 6 \\
\text { anos }\end{array}$ & $\begin{array}{l}\text { US\$ } 50 \\
\text { US\$ } 120\end{array}$ & $\begin{array}{l}\text { Provimento de liquidez e } \\
\text { evitar a insolvência de } \\
\text { instituições financeiras }\end{array}$ \\
\hline QE I-MBS & Nov/08 & Ago/10 & $\begin{array}{l}\text { Detentores de títulos } \\
\text { hipotecários }\end{array}$ & Moeda & O próprio título & -- & US\$ 1250 & \multirow{4}{*}{$\begin{array}{l}\text { Melhoria das condições } \\
\text { dos mercados hipotecários } \\
\text { (Empréstimo e taxa de } \\
\text { juros de longo prazo) }\end{array}$} \\
\hline QE I - Dívida & Nov/08 & Ago/10 & Agências & Moeda & O próprio título & -- & US\$ 175 & \\
\hline $\begin{array}{l}\text { QE I - Titulos } \\
\text { Tesouro }\end{array}$ & Mar/09 & Out/09 & $\begin{array}{c}\text { Detentores de títulos } \\
\text { públicos }\end{array}$ & Moeda & O próprio título & -- & US\$ 300 & \\
\hline $\begin{array}{c}\text { QE II - Titulos } \\
\text { Tesouro }\end{array}$ & Nov/10 & Dez/12 & $\begin{array}{l}\text { Detentores de títulos } \\
\text { públicos }\end{array}$ & Moeda & O próprio título & -- & US\$ 600 & \\
\hline MEP & Set/11 & Dez/12 & $\begin{array}{l}\text { Detentores de títulos } \\
\text { públicos de longo } \\
\text { prazo }\end{array}$ & $\begin{array}{l}\text { Títulos } \\
\text { públicos } \\
\text { de CP }\end{array}$ & $\mathrm{O}$ próprio título & -- & US\$ 667 & \multirow{3}{*}{$\begin{array}{l}\text { Melhoria das condições } \\
\text { gerais dos mercados } \\
\text { financeiros (Empréstimo e } \\
\text { taxa de juros de longo } \\
\text { prazo) }\end{array}$} \\
\hline QE III - MBS & Set/12 & -- & $\begin{array}{c}\text { Detentores de títulos } \\
\text { hipotecários }\end{array}$ & Moeda & $\mathrm{O}$ próprio título & -- & US\$ 40 & \\
\hline $\begin{array}{c}\text { QE III } \\
\text { Titulos Tesouro }\end{array}$ & $\mathrm{Jan} / 13$ & -- & $\begin{array}{l}\text { Detentores de títulos } \\
\text { públicos de longo } \\
\text { prazo }\end{array}$ & $\begin{array}{l}\text { Títulos } \\
\text { públicos } \\
\text { de CP }\end{array}$ & O próprio título & -- & US\$ 45 & \\
\hline
\end{tabular}

Nota: (1) Impacto médio mensal e valor máximo sobre o balanço do FED ao longo da execução do programa, em bilhões de dólares.

Fonte: Federal Reserve Bank of New York (2008), Board of Governors of the Federal Reserve System (2014) e Cecioni et al. (2011). 


\section{Anexo 2}

Síntese de trabalhos empíricos acerca da efetividade das PMNC adotadas pelo Fed

\begin{tabular}{|c|c|c|c|c|}
\hline Artigo & Programa & Metodologia & Variável de interesse & Resultados \\
\hline $\begin{array}{l}\text { Taylor and } \\
\text { Williams (2010) }\end{array}$ & TAF & Estudo de eventos & $\begin{array}{l}\text { Spread da libor em relação a taxa de } \\
\text { Overnight swap interbancário (OIS) }\end{array}$ & $\begin{array}{c}\text { O programa não teve impacto significativo em } \\
\text { relação ao spread da libor-IOS }\end{array}$ \\
\hline $\begin{array}{l}\text { McAndrews, } \\
\text { Sarkar and Wang } \\
(2008)\end{array}$ & TAF & Estudo de eventos & $\begin{array}{l}\text { Spread da libor em relação a taxa de } \\
\text { Overnight swap interbancário (OIS) }\end{array}$ & $\begin{array}{l}\text { O programa promoveu a redução do spread } \\
\text { libor-OIS de } 3 \text { meses em } 50 \text { pontos bases }\end{array}$ \\
\hline Wu (2010) & TAF & Estudo de eventos & $\begin{array}{l}\text { Spread da libor em relação a taxa de } \\
\text { Overnight swap interbancário (OIS) }\end{array}$ & $\begin{array}{l}\text { O programa promoveu a redução do spread da } \\
\text { libor-OIS de } 3 \text { meses em } 50 \text { pontos bases }\end{array}$ \\
\hline $\begin{array}{l}\text { Sarkar and } \\
\text { Shrader (2010) }\end{array}$ & TAF & Regressão OLS & $\begin{array}{l}\text { Spread da libor em relação a taxa de } \\
\text { Overnight swap interbancário (OIS) }\end{array}$ & $\begin{array}{c}\text { O programa promoveu a redução do spread da } \\
\text { libor-OIS de } 3 \text { meses em } 0,1 \text { e } 0,5 \text { pontos bases } \\
\text { para cada um bilhão }\end{array}$ \\
\hline $\begin{array}{l}\text { Christensen, } \\
\text { Lopez and } \\
\text { Rudebusch (2009) }\end{array}$ & TAF & $\begin{array}{l}\text { Modelo de livre } \\
\text { arbitragem e termo } \\
\text { estrutural; analise } \\
\text { contra factual }\end{array}$ & Taxa libor & $\begin{array}{l}\text { O programa promoveu a redução do risco de } \\
\text { liquides da taxa libor de } 3 \text { meses em } 70 \text { pontos } \\
\text { bases }\end{array}$ \\
\hline Thorton (2010) & TAF & Estudo de eventos & $\begin{array}{c}\text { Ted spread (diferença entre a taxa } \\
\text { interbancária em relação aos títulos "t-bill" } \\
\text { do governo americano) }\end{array}$ & $\begin{array}{l}\text { O programa não teve impacto significativo no } \\
\text { prêmio de liquidez do mercado de libor }\end{array}$ \\
\hline Shin (2011) & TAF & Análise de dados & Liquidez dos bancos estrangeiros & \multirow{2}{*}{$\begin{array}{l}\text { O programa foi importante para suprir a } \\
\text { necessidade de curto prazo dos bancos } \\
\text { estrangeiro de moeda americana }\end{array}$} \\
\hline Benmelech (2012) & TAF & Regressão OLS & $\begin{array}{l}\text { Volume de empréstimos do programa por } \\
\text { tomador (doméstico e estrangeiro) }\end{array}$ & \\
\hline $\begin{array}{l}\text { Fleming, Hrung } \\
\text { and Keane (2010) }\end{array}$ & TSLF & Regressão OLS & $\begin{array}{l}\text { As taxas repo (taxa de desconto no qual o } \\
\text { banco central recompra títulos do governo } \\
\text { dos bancos comerciais) e spread entre } \\
\text { acordos de recompra e acordos de } \\
\text { recompra do Tesouro com base em outros } \\
\text { colaterais menos líquido }\end{array}$ & $\begin{array}{l}\text { O programa promoveu a redução na taxa repo } \\
\text { dos títulos de dívida de agência e títulos MBS } \\
\text { de agências e do tesouro em } 0,4 \text { pontos bases } \\
\text { para cada um bilhão de títulos utilizados }\end{array}$ \\
\hline
\end{tabular}

Continua... 
Continuação

\begin{tabular}{|c|c|c|c|c|}
\hline Artigo & Programa & Metodologia & Variável de interesse & Resultados \\
\hline $\begin{array}{l}\text { Hrung and } \\
\text { Seligman (2011) }\end{array}$ & TSLF & Regressão OLS & $\begin{array}{l}\text { Spread entre a taxa básica (Fed funds rate) } \\
\text { os títulos do tesouro }\end{array}$ & $\begin{array}{l}\text { O programa promoveu a redução na taxa repo } \\
\text { dos títulos de dívida de agência e títulos MBS } \\
\text { de agências e do tesouro em } 1 \text { ponto percentual } \\
\text { para cada um bilhão de títulos utilizados }\end{array}$ \\
\hline $\begin{array}{l}\text { Baba at al (2008) } \\
\text { e Baba and Packer } \\
(2009)\end{array}$ & RCA & $\begin{array}{l}\text { Análise de } \\
\text { componente } \\
\text { principal }\end{array}$ & $\begin{array}{l}\text { Desvios da paridade de juros coberto de } \\
\text { swap de FX }\end{array}$ & $\begin{array}{l}\text { O programa promoveu a redução na relação } \\
\text { euro - dólar (EUR /USD FX swap) em } 30 \\
\text { pontos base }\end{array}$ \\
\hline Jones (2009) & n.a. & Análise de dados & $\begin{array}{l}\text { Relação entre o Câmbio e a taxa de juros } \\
\quad \text { (paridade coberta da taxa de juros) }\end{array}$ & $\begin{array}{l}\text { Questionam a validade da teoria da paridade } \\
\text { coberta da taxa de juros para o período da crise } \\
2008\end{array}$ \\
\hline $\begin{array}{l}\text { Duygan-Bump, } \\
\text { Parkinson, } \\
\text { Rosengren, Suarez } \\
\text { and Willen (2010) }\end{array}$ & AMLF & Estudo de eventos & $\mathrm{ABCP}$ e commercial paper & $\begin{array}{l}\text { O programa forneceu uma importante fonte de } \\
\text { liquidez para o mercado de ABCP além da } \\
\text { redução de } 80 \text { pontos bases na taxa de juros } \\
\text { destes papeis. }\end{array}$ \\
\hline $\begin{array}{l}\text { Anderson and } \\
\text { Gascon (2009) }\end{array}$ & CPFF & $\begin{array}{l}\text { Analise de dados } \\
\text { (estatística } \\
\text { descritiva) }\end{array}$ & Commercial paper & $\begin{array}{c}\text { O programa promoveu a melhora do mercado } \\
\text { de commercial papers, estimulando a emissão } \\
\text { de novos títulos }\end{array}$ \\
\hline $\begin{array}{l}\text { Adrian et al } \\
(2010)\end{array}$ & CPFF & $\begin{array}{l}\text { Analise de dados } \\
\text { (estatística } \\
\text { descritiva) }\end{array}$ & Commercial paper & $\begin{array}{l}\text { O programa promoveu um aumento do prazo } \\
\text { das emissões de comercial papers, além da } \\
\text { redução do spread de juros }\end{array}$ \\
\hline Duca (2011) & CPFF & $\begin{array}{l}\text { Regressão linear e } \\
\text { modelo VEC }\end{array}$ & $\begin{array}{l}\text { Taxa de juros e liquidez de commercial } \\
\text { papers }\end{array}$ & $\begin{array}{c}\text { O programa impediu, conjuntamente com } \\
\text { outras medidas, o colapso do mercado } \\
\text { monetário }\end{array}$ \\
\hline $\begin{array}{l}\text { Agarwal et al } \\
(2010)\end{array}$ & TALF & Estudo de eventos & Volume e spread das ABS & $\begin{array}{c}\text { O programa estimulou a retomada das emissões } \\
\text { de ABS e queda do spread (entre } 200 \text { e } 150 \\
\text { pontos bases) }\end{array}$ \\
\hline $\begin{array}{l}\text { Campbell, Covitz, } \\
\text { Nelson and Pence } \\
(2011)\end{array}$ & TALF & Estudo de eventos & Spread sobre as ABS e CMBS elegíveis; & $\begin{array}{l}\text { O programa auxiliou a recuperação de emissões } \\
\text { de securities, com destaque para a queda do } \\
\text { spread das ABS (entre } 10 \text { e } 60 \text { pontos bases) e } \\
\text { CMBS (entre } 50 \text { e } 150 \text { pontos bases) }\end{array}$ \\
\hline
\end{tabular}

Continua... 


\begin{tabular}{|c|c|c|c|c|}
\hline \multicolumn{5}{|l|}{ Continuação } \\
\hline Artigo & Programa & Metodologia & Variável de interesse & Resultados \\
\hline $\begin{array}{l}\text { Stroebel and } \\
\text { Taylor (2009) }\end{array}$ & $\begin{array}{c}\text { Compra de } \\
\text { dívida e MBS } \\
\text { de agência (QE } \\
\text { I) }\end{array}$ & Estudo de eventos & Spread sobre as MBS & $\begin{array}{l}\text { O programa promoveu a redução no spread das } \\
\text { MBS (entre } 30 \text { e } 60 \text { pontos bases) embora a sua } \\
\text { eficácia seja questionada pelos autores }\end{array}$ \\
\hline $\begin{array}{l}\text { Hancock and } \\
\text { Passmore (2011) }\end{array}$ & $\begin{array}{c}\text { Compra de } \\
\text { dívida e MBS } \\
\text { de agência }(\mathrm{QE} \\
\text { I) }\end{array}$ & Regressão OLS & $\begin{array}{l}\text { Spread sobre as MBS e taxa de juros dos } \\
\text { mercados hipotecas }\end{array}$ & $\begin{array}{l}\text { O programa promoveu a redução no spread das } \\
\text { MBS (cerca de } 85 \text { pontos após o anuncio e mais } \\
50 \text { pontos base durante a execução do } \\
\text { programa) e o reestabelecimento do mercado de } \\
\text { MBS }\end{array}$ \\
\hline $\begin{array}{l}\text { Fuster and Willen } \\
(2010)\end{array}$ & $\begin{array}{c}\text { Compra de } \\
\text { dívida e MBS } \\
\text { de agência (QE } \\
\text { I) }\end{array}$ & Estudo de eventos & $\begin{array}{l}\text { Taxa de juros e volume de empréstimos } \\
\text { dos mercados hipotecários }\end{array}$ & $\begin{array}{l}\text { O programa promoveu a retomada parcial do } \\
\text { mercado de hipotecas (principalmente } \\
\text { refinanciamento) e a redução na taxa de } \\
\text { hipoteca para mutuários de alta qualidade }\end{array}$ \\
\hline $\begin{array}{l}\text { Gagnon et al } \\
(2011)\end{array}$ & $\begin{array}{c}\text { Compra de } \\
\text { títulos públicos } \\
\text { (QEI) }\end{array}$ & Estudo de eventos & $\begin{array}{l}\text { Taxa de juros dos títulos do governo com } \\
\text { vencimento para } 10 \text { anos }\end{array}$ & $\begin{array}{l}\text { O programa promoveu a queda na taxa de juros } \\
\text { dos títulos do tesouro (cerca de } 90 \text { pontos } \\
\text { bases) com vencimento de } 10 \text { anos }\end{array}$ \\
\hline Yellen (2011b) & $\begin{array}{l}\text { Compra de } \\
\text { títulos públicos } \\
\text { (QEI) }\end{array}$ & Estudo de eventos & $\begin{array}{c}\text { Anuncio e execução do QEI sobre as taxas } \\
\text { de juros dos títulos do governo com } \\
\text { vencimento para } 10 \text { anos }\end{array}$ & $\begin{array}{l}\text { O programa promoveu a queda na taxa de juros } \\
\text { dos títulos do tesouro (cerca de } 107 \text { pontos } \\
\text { bases) com vencimento de } 10 \text { anos }\end{array}$ \\
\hline $\begin{array}{l}\text { D'Amico and } \\
\text { King (2010) }\end{array}$ & $\begin{array}{c}\text { Compra de } \\
\text { títulos públicos } \\
\text { (QEI) }\end{array}$ & $\begin{array}{l}\text { Estudo de dados em } \\
\text { painel }\end{array}$ & $\begin{array}{l}\text { Taxa de juros dos títulos do governo de } \\
\text { longo prazo (várias maturidades) }\end{array}$ & $\begin{array}{l}\text { O programa (compra de } 400 \text { bilhões) promoveu } \\
\text { a queda na taxa de juros mais longas dos títulos } \\
\text { do tesouro (cerca de } 67 \text { pontos bases) }\end{array}$ \\
\hline $\begin{array}{l}\text { Krishnamurthy } \\
\text { and Vissing- } \\
\text { Jorgensen (2011) }\end{array}$ & $\begin{array}{l}\text { Compra de } \\
\text { títulos públicos } \\
\text { (QEI e QEII) }\end{array}$ & Estudo de eventos & $\begin{array}{l}\text { Taxa de juros dos títulos do governo de } \\
\text { longo prazo (várias maturidades) }\end{array}$ & $\begin{array}{c}\text { O programa promoveu a queda na taxa de juros } \\
\text { mais longas dos títulos do tesouro (QEI cerca } \\
\text { de } 100 \text { pontos bases e QEII cerca de } 30 \text { pontos } \\
\text { bases) }\end{array}$ \\
\hline Swanson (2011) & $\begin{array}{l}\text { Compra de } \\
\text { títulos públicos } \\
\text { (QEII) }\end{array}$ & Estudo de eventos & $\begin{array}{l}\text { Taxa de juros dos títulos do governo com } \\
\text { vencimento de } 10 \text { anos }\end{array}$ & $\begin{array}{l}\text { O programa promoveu a queda na taxa de juros } \\
\text { dos títulos do tesouro (cerca de } 15 \text { pontos } \\
\text { bases) com vencimento de } 10 \text { anos }\end{array}$ \\
\hline
\end{tabular}

Continua... 


\begin{tabular}{|c|c|c|c|c|}
\hline \multicolumn{5}{|l|}{ Continuação } \\
\hline Artigo & Programa & Metodologia & Variável de interesse & Resultados \\
\hline $\begin{array}{l}\text { Hamilton e Wu } \\
\text { (2011); Vayanos e } \\
\text { Vila (2009) e } \\
\text { Gagnon et al. } \\
\text { (2010) e } \\
\text { Greenwood e } \\
\text { Vayanos (2010) }\end{array}$ & $\begin{array}{l}\text { Troca de } \\
\text { maturidade de } \\
\text { títulos do } \\
\text { governo }\end{array}$ & Series temporais & $\begin{array}{l}\text { Taxa de juros dos títulos do governo de } \\
\text { longo prazo (várias maturidades) }\end{array}$ & $\begin{array}{c}\text { O programa promoveu a queda na taxa de juros } \\
\text { mais longas dos títulos do tesouro (os } \\
\text { resultados obtidos pelos autores geraram } \\
\text { resultados que variam entre } 14 \text { e } 60 \text { pontos } \\
\text { bases) }\end{array}$ \\
\hline $\begin{array}{l}\text { Baumeister and } \\
\text { Benati (2010) }\end{array}$ & $\begin{array}{l}\text { Compra de } \\
\text { títulos públicos } \\
\text { (QEI) }\end{array}$ & Estudo de eventos & Taxa de crescimento do PIB & $\begin{array}{l}\text { O programa promoveu uma queda na taxa de } \\
\text { juros de longo prazo, afetando positivamente a } \\
\text { atividade econômica (na ausência do QEI, a } \\
\text { economia americana teria seu PIB reduzido em } \\
10 \% \mathrm{em} 2010 \text { ) }\end{array}$ \\
\hline $\begin{array}{l}\text { Del Negro et al } \\
(2010)\end{array}$ & QEI & DSGE & Taxa de crescimento do PIB & $\begin{array}{l}\text { O programa afetou positivamente a atividade } \\
\text { econômica (na ausência do QEI, a economia } \\
\text { americana teria entrado em colapso) }\end{array}$ \\
\hline Chung (2011) & QEI e QEII & DSGE & $\begin{array}{l}\text { Juros, taxa de crescimento do PIB e de } \\
\text { desemprego }\end{array}$ & $\begin{array}{l}\text { O programa afetou positivamente a atividade } \\
\text { econômica e emprego (no ano de } 2012 \mathrm{o} \\
\text { impacto foi de } 3 \% \text { no PIB e de menos } 1,5 \% \text { na } \\
\text { taxa de desemprego) }\end{array}$ \\
\hline $\begin{array}{l}\text { Meinuscusch et al } \\
(2014)\end{array}$ & $\begin{array}{l}\text { QEI, QEII e } \\
\text { QEIII }\end{array}$ & Estudo de eventos & $\begin{array}{c}\text { Taxa de crescimento do PIB e de } \\
\text { desemprego }\end{array}$ & $\begin{array}{l}\text { O programa afetou positivamente a atividade } \\
\text { econômica e emprego (o impacto do programa } \\
\text { foi de } 1 \% \text { no PIB e - de } 0,4 \% \text { na taxa de } \\
\text { desemprego após o primeiro ano) }\end{array}$ \\
\hline
\end{tabular}

Fonte: Elaboração própria com base em Cecioni et al. (2011). 